\title{
Design and Function of Superfast Muscles: New Insights into the Physiology of Skeletal Muscle
}

\author{
Lawrence C. Rome \\ Department of Biology, University of Pennsylvania, Philadelphia, Pennsylvania 19104; \\ The Marine Biological Laboratory, Woods Hole, Massachusetts 02543; \\ email: lrome@sas.upenn.edu
}

Key Words parvalbumin, $\mathrm{Ca}^{2+}$ release, $\mathrm{Ca}^{2+}$ uptake, cross-bridges, adaptation, sound production

- Abstract Superfast muscles of vertebrates power sound production. The fastest, the swimbladder muscle of toadfish, generates mechanical power at frequencies in excess of $200 \mathrm{~Hz}$. To operate at these frequencies, the speed of relaxation has had to increase approximately 50 -fold. This increase is accomplished by modifications of three kinetic traits: $(a)$ a fast calcium transient due to extremely high concentration of sarcoplasmic reticulum (SR)-Ca ${ }^{2+}$ pumps and parvalbumin, (b) fast off-rate of $\mathrm{Ca}^{2+}$ from troponin $\mathrm{C}$ due to an alteration in troponin, and $(c)$ fast cross-bridge detachment rate constant ( $g$, 50 times faster than that in rabbit fast-twitch muscle) due to an alteration in myosin. Although these three modifications permit swimbladder muscle to generate mechanical work at high frequencies (where locomotor muscles cannot), it comes with a cost: The high $g$ causes a large reduction in attached force-generating cross-bridges, making the swimbladder incapable of powering low-frequency locomotory movements. Hence the locomotory and sound-producing muscles have mutually exclusive designs.

\section{INTRODUCTION: THE FUNCTION OF SUPERFAST MUSCLES}

Our perception of speed is greatly influenced by movement we can see. Most animal movement, such as the running of a squirrel or mouse, is macroscopic. These movements seem fast until one watches the wings of a hovering humming bird. It is a natural assumption that these fast movements are powered by the fastest vertebrate muscles, but in fact this is not the case. The fastest muscles are used to produce sounds, and the movements occur inside the body, and usually, but not always (e.g., rattlesnake), only the sound that is produced (and no external movement) can be detected. These superfast muscles produce sound from approximately $90 \mathrm{~Hz}$ to approximately $250 \mathrm{~Hz}$.

There has been considerable research through the years concerning the behavior of sound production, the neural control of muscle function, and the morphology 
of the muscle (1-3). This review focuses exclusively on more recent work, begun less than a decade ago, on the physiology and mechanics of superfast muscles (4). The recent progress in understanding how these muscles function has been based on integrative and comparative approaches. Below, we discuss these general approaches before discussing the particulars of superfast muscle.

\section{THE IMPORTANCE OF INTEGRATIVE APPROACHES TO THE STUDY OF MUSCLE FUNCTION}

Vertebrates perform a tremendous variety of motor tasks, ranging from making explosive movements taking less than $\sim 50 \mathrm{~ms}$, to swimming thousands of miles in the ocean, to producing sound at several hundred hertz for communication. These activities require different outputs from the muscles (5). Accordingly, research over the past several decades has revealed that muscle tissue has tremendous diversity, perhaps more than any other tissue.

Although it has been clear for many years that contractile properties of the muscles themselves are key in understanding muscular system design, over the past 15 years it has become equally clear that one cannot study the contractile properties in isolation. Rather, the whole muscular system must be examined because one cannot appreciate the contractile properties of the fibers without examining the other components (e.g., joints, muscle moments, masses, kinematics of movement) to which they are matched. Hence the field has moved toward comprehensive integrative studies (6-9). This movement represents a turning point in the field of integrative muscle physiology and biomechanics.

This current revolution in integrative muscle physiology stems from both intellectual and technological improvements in the fields of biophysics, quantitative physiology, quantitative biochemistry, biomechanics, and musculoskeletal modeling. However, these advances would not have been possible without the recognition of the need for, and the development of, exceptional experimental animal models. Although today, few would consider using the mechanics and energetics of frog muscle (10) to try to understand the mechanics and energetics of running lizards (11), such practice was considered at the cutting edge of experimentation as recently as $20-25$ years ago (reviewed in 12 ). Hence, by providing exceptional experimental models in which all pertinent measurements could be made in a single species, comparative physiology has played a major role in understanding muscle function from the molecular to the whole animal level.

\section{COMPARATIVE PHYSIOLOGY: PURE AND EXTREME MODELS PROVIDE A LINCHPIN OF MODERN BIOLOGY}

The importance of comparative physiology as a central approach underlying much of the modern study of biology is not fully appreciated. Perhaps nowhere is this better illustrated than the study of superfast muscle, in which comparative 
physiology has been the enabler of a large number of approaches from other fields. In this case of superfast muscles, comparative physiology provides an opportunity to utilize a pure tissue with extreme modifications. As unfolds below, these combine with great effect.

The approaches used in studying superfast muscles represent the confluence of many fields, including cellular and molecular physiology, biophysics, integrative physiology, quantitative physiology, quantitative biochemistry, quantitative ultrastructure, modeling, and neuroethology. The linchpin to this interdisciplinary approach, however, is the experimental models provided by comparative physiology - in this case, fish muscles that express a single, pure fiber type. The purity of the tissue permits the dissection of bundles of fibers literally of any size, which, in turn, permits us to perform diverse studies ranging from single- (or split-) fiber biophysics and mechanics (using micrograms of tissue) to intact muscle energetics (with milligrams of tissue) to biochemical purification and quantification of muscle proteins (grams to kilograms of tissue).

Aside from providing information about the workings of superfast muscles, studying these extremes also provides insight into the way in which normal muscle works. For instance, different muscle types from our experimental model, the toadfish, vary 50-fold in speed and include the fastest and among the slowest in the whole vertebrate subphylum. Understanding how each of these extremes function can give an important perspective absent when examining relatively small differences in function (e.g., between IIx and IIa fibers in mammals). As we also see below, looking at extremes can permit us to see functional differences clearly, whereas the smaller differences in more normal muscles can be easily lost in the noise. Finally, extreme designs may require very high concentrations of some compounds [e.g., parvalbumin (PARV)], which permits the development of new types of techniques that can elucidate new mechanisms.

\section{TOADFISH (OPSANUS TAU) SWIMBLADDER MUSCLE: THE KEY MODEL}

In general, fish provide excellent models for studying muscular system design because their different fiber types are anatomically separated; hence (a) differentsized bundles of fibers pure in fiber type can be isolated for various experiments and $(b)$ the usage of different fibers during normal activity can be monitored easily by electromyography. Toadfish is exceptional because its slow-twitch red muscle, used for swimming at $<1 \mathrm{~Hz}$, is among the slowest twitch fibers known (twitch half-width $\approx 500 \mathrm{~ms}$ at $15^{\circ} \mathrm{C}$ ), whereas the superfast toadfish swimbladder muscle used for sound production at $100 \mathrm{~Hz}$ (at $15^{\circ} \mathrm{C} ;>200 \mathrm{~Hz}$ at $25^{\circ} \mathrm{C}$ ) is the fastest vertebrate muscle ever measured (twitch half-width $\approx 10 \mathrm{~ms}$ ). Therefore, in this one species, it is possible to examine the function of three muscle fiber types (including the intermediate-speed fast-twitch white muscle) whose twitch speed and speed of operation in vivo vary $\sim 50$-fold, spanning nearly the full range found in vertebrates. 


\section{THE ACTIVATION-RELAXATION CYCLE: WHAT IS NEEDED FOR SPEED?}

\section{Molecular Basis of Activation and Relaxation in Toadfish}

The importance of muscle activation and relaxation in muscle design has been appreciated for 20 years (13). Workloop experiments on locomotory and soundproducing muscles $(7,9,14-16)$ have demonstrated that the kinetics of activation and relaxation are critical for in vivo performance. Until approximately 10 years ago, research dealt with the kinetics of activation and relaxation phenomenologically. This approach was necessary because, although the basic mechanisms of activation and relaxation were known for some time, a quantitative understanding of which processes set twitch speed or how $\mathrm{Ca}^{2+}$ cycles during normal contraction had been lacking. The kinetics of activation and relaxation are complex and require the integration of many components for which values remain largely unknown. Activation is usually thought to consist of $\mathrm{Ca}^{2+}$ release from the sarcoplasmic reticulum (SR) (Figure 1, step 1) and $\mathrm{Ca}^{2+}$ binding to troponin $\mathrm{C}$ (TNC) (Figure 1, step 2). Measurements and models show that this is rapid (i.e., $10 \mathrm{~ms}$ ) (17). However, for purposes of understanding muscle function during locomotion or other motor behaviors, maximal activation is not achieved until cross-bridges attach and generate force (or undergo transitions between states) (Figure 1, step 3). This takes considerably longer and lags well behind formation of the $\mathrm{Ca}^{2+}$-TNC complex. Relaxation is even more complex. During and following $\mathrm{Ca}^{2+}$ release, $\mathrm{Ca}^{2+}$ is sequestered by the SR (Figure 1, step 4) and also becomes bound to PARV, which is in relatively high concentration in frog muscle and fish white muscle. Myoplasmic $\left[\mathrm{Ca}^{2+}\right]$ drops, causing $\mathrm{Ca}^{2+}$ to dissociate from TNC (Figure 1, step 5), cross-bridges to detach (Figure 1, step 6), and force to drop to zero.

Although the phenomenological approach was a necessity, it was limiting because it neither explained what molecular properties must be changed to alter the kinetics of the muscle to appropriate values nor how different components are related. Hence, we applied a molecular approach to gain a better understanding of these issues. The rate of relaxation varies tremendously among different types of muscle (reviewed in Reference 18). Despite the many experiments that examined the individual components involved in muscle relaxation, little was known about how relaxation speed was set. One reason for this was that measurements of the different components were made on different species. Furthermore, sufficient information to develop an integrative understanding of relaxation had been collected for only one species (frog) $(17,19-22)$; thus, there was no other muscle type to which this could be compared.

Hence, the main goal was to determine the principal factors that set the kinetics of twitches in three fiber types of toadfish whose twitch duration varies 50 -fold. Because twitch duration is set primarily by relaxation, we measured the kinetics of the three systems involved in relaxation (Figure 1): (a) $\mathrm{Ca}^{2+}$ reuptake, (b) $\mathrm{Ca}^{2+}$ off-rate from troponin (indicated as a shift in force-pCa relationship), and 


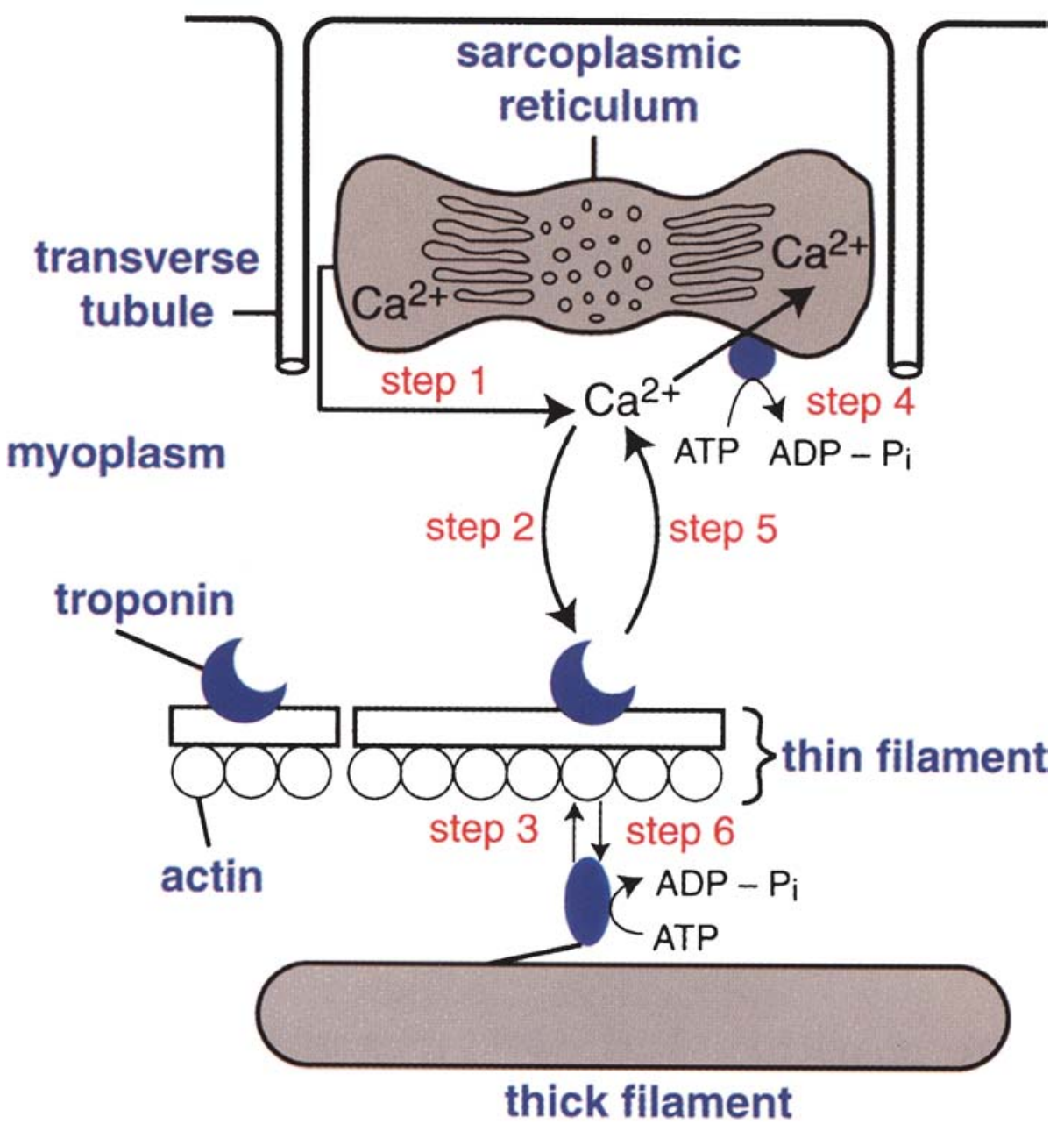

Figure 1 The major kinetic steps in muscle activation and relaxation. Activation occurs in steps 1-3, and relaxation in steps 4-6. (Step1) $\mathrm{Ca}^{2+}$ is released from the sarcoplasmic reticulum into the myoplasm. (Step 2) $\mathrm{Ca}^{2+}$ binds to troponin, releasing inhibition of the thin filament. (Step 3) Cross-bridges attach and generate force. (Step 4) $\mathrm{Ca}^{2+}$ is resequestered from the myoplasm by the $\mathrm{Ca}^{2+}$ pumps. (Step 5) $\mathrm{Ca}^{2+}$ comes off troponin, thereby preventing subsequent cross-bridge attachment. (Step 6) Cross-bridges detach. For a muscle to relax rapidly, steps 4-6 all must occur rapidly. 
TABLE 1 Cross-bridge kinetic constants, force, and concentration of constituent protein in toadfish muscle*

\begin{tabular}{|c|c|c|c|c|c|c|c|}
\hline Fiber & $f\left(s^{-1}\right)$ & $g\left(s^{-1}\right)$ & $f /(f+g)$ & $\begin{array}{l}\text { Force }^{\mathrm{a}} \\
\left(\mathbf{k N} / \mathbf{m}^{2}\right)\end{array}$ & $\begin{array}{l}\text { MHC } \\
(\mu \mathbf{M})^{b}\end{array}$ & $\begin{array}{l}\text { TNC } \\
(\mu \mathbf{M})\end{array}$ & $\begin{array}{l}\text { PARV } \\
(\mathbf{m M})^{\mathrm{c}}\end{array}$ \\
\hline Red & 6.6 & 2.8 & 70 & 244 & 117 & - & \\
\hline White & 16.2 & 10.3 & 61 & 192 & 167 & - & \\
\hline Swim & 12.7 & 108 & 10.5 & 24 & 69 & 35 & 1.5 \\
\hline \multicolumn{8}{|c|}{$\begin{array}{l}{ }^{*} \text { All data are from Reference } 23 \text { except for the TNC and PARV concentrations (B. Tikunov, personal } \\
\text { communication). MHC, myosin heavy chain; TNC, troponin C, PARV, parvalbumin. }\end{array}$} \\
\hline
\end{tabular}

(c) cross-bridge detachment. To a first approximation, these processes occured in series. Thus, as twitch speed increased in different fiber types, so did the rate of each one of the processes (Figures 2-5; Table 1) $(4,23)$.

Figure 2 shows that there was a systematic acceleration of the $\mathrm{Ca}^{2+}$ transient as the twitch speed increased. The $\mathrm{Ca}^{2+}$ transient in the sonic muscles is the fastest ever measured for any fiber type (a half-width of $\sim 3.4 \mathrm{~ms}$ at $16^{\circ} \mathrm{C}$ and $1.5 \mathrm{~ms}$ at $25^{\circ} \mathrm{C}$ ) (4). The importance of the $\mathrm{Ca}^{2+}$ transient duration in setting the twitch duration is evident in Figure 2, which shows that between the slow-twitch red fibers and the superfast-twitch swimbladder fibers, the half-widths of the $\mathrm{Ca}^{2+}$ transient and the twitch sped up in parallel (by $\sim 50$-fold).

The significance of a fast $\mathrm{Ca}^{2+}$ transient is most apparent during repetitive stimulation. During stimulation of slow red muscle at a modest $3.5 \mathrm{~Hz}$ (Figure 3), the time course of $\mathrm{Ca}^{+2}$ uptake is so slow that $\left[\mathrm{Ca}^{2+}\right]$ does not have time to return to baseline between stimuli. Even the lowest myoplasmic $\left[\mathrm{Ca}^{2+}\right]$ between stimuli was above the threshold required for force generation in this fiber type, thus resulting in a partially fused tetanus. By contrast, the swimbladder muscle's $\mathrm{Ca}^{2+}$ transient is so rapid that even with $67 \mathrm{~Hz}$ stimulation, the return of $\left[\mathrm{Ca}^{2+}\right]$ to baseline between stimuli is complete (Figure 3, right; note the 50-times faster time base). In addition, $\left[\mathrm{Ca}^{2+}\right]$ is below the threshold for force generation for more than half of the time in all but the first stimulus. Hence, the $\mathrm{Ca}^{2+}$ transient is sufficiently rapid to permit the oscillation in force required for sound production.

Even though $\left[\mathrm{Ca}^{2+}\right]$ returns rapidly to baseline, the swimbladder fiber could not relax quickly unless its troponin rapidly released bound $\mathrm{Ca}^{2+}$ (Figure 1, step 5). Indeed, kinetic modeling (figure 3 in Reference 4 ) indicates that if the swimbladder troponin had the off-rate $\left(\mathrm{k}_{\text {off }}\right)$ for $\mathrm{Ca}^{2+}$ estimated for fast-twitch fibers of frog $\left(115 \mathrm{~s}^{-1}\right)$, then $\mathrm{Ca}^{2+}$ would not unbind from troponin sufficiently rapidly to permit the observed rapid fall in force. Figure 4 shows a systematic right shift in the force$\mathrm{pCa}$ relationship with increasing twitch speed. The threefold right shift of the force versus $\left[\mathrm{Ca}^{2+}\right]$ relationship of swimbladder fibers with respect to frog fibers was 

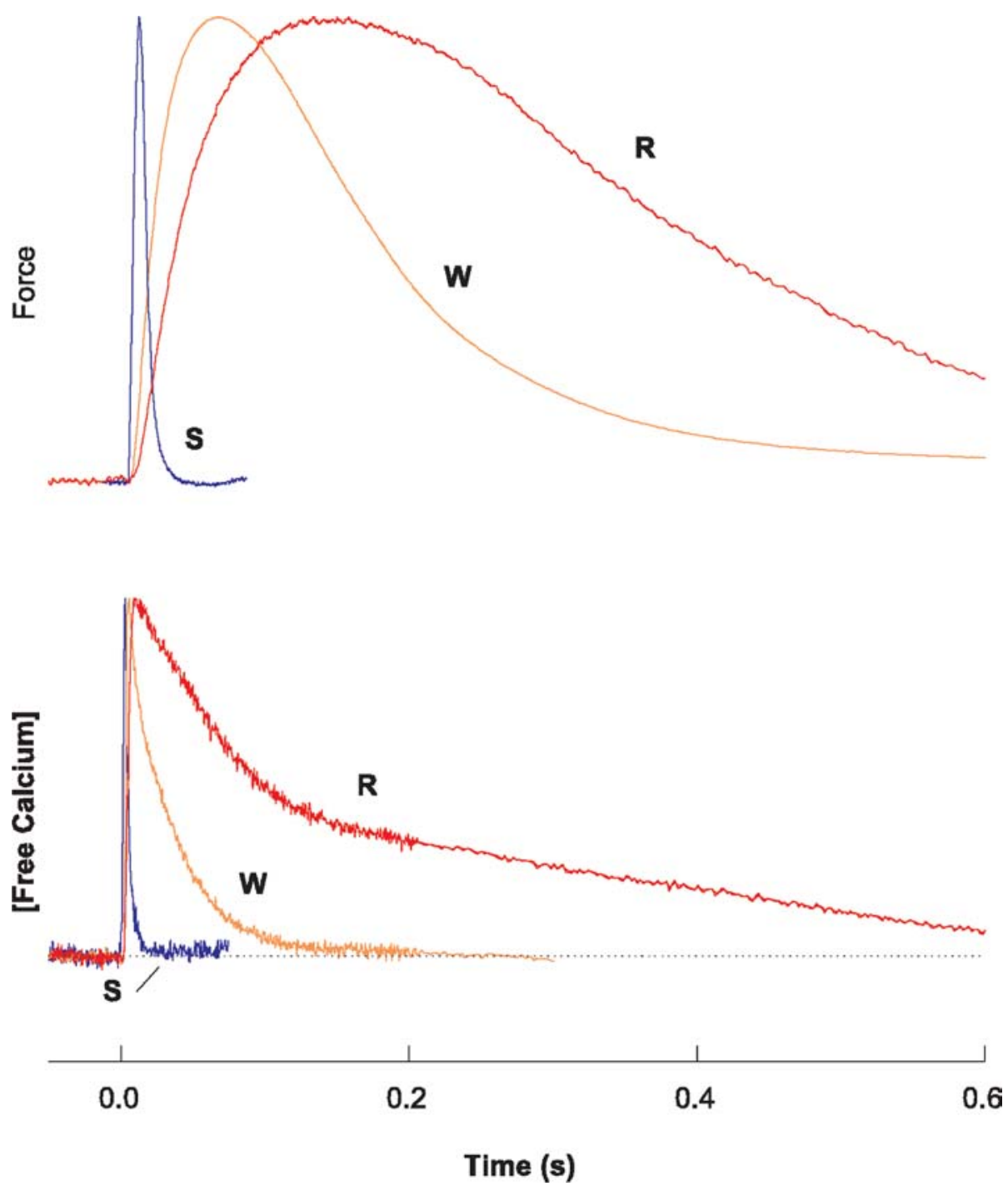

Figure 2 Twitch tension (top) and calcium transients (bottom) of three fiber types from toadfish at $15^{\circ} \mathrm{C}$. In each case, the force and the calcium records have been normalized to their maximum value. The twitch and calcium transient become briefer going from the slowtwitch red fiber ( $\mathrm{R}$, red $)$, to the fast-twitch white fiber (W, white), to the superfast-twitch swimbladder fiber (S, blue). Based on Reference 4. 

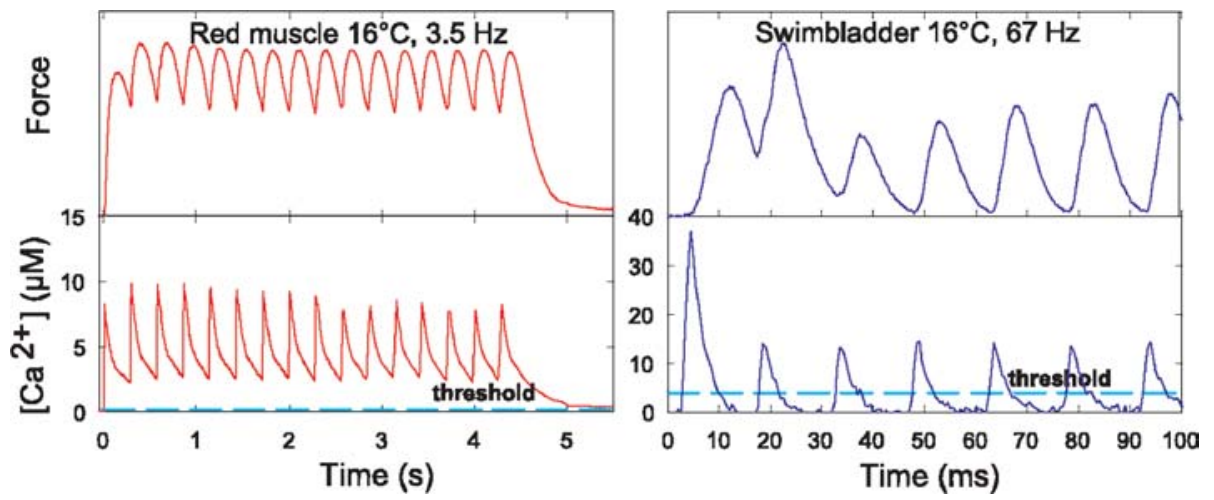

Figure 3 Force production (top) and calcium transients (bottom) during repetitive stimulation. (Left) Slow-twitch red fiber (red) stimulated at $3.5 \mathrm{~Hz}$. The threshold $\left[\mathrm{Ca}^{2+}\right]$ for force generation was derived by force-pCa experiment on skinned fibers (from Figure 4) and is shown with a light blue dashed line. (Right) Swimbladder fiber (blue) stimulated at $67 \mathrm{~Hz}$. The $\left[\mathrm{Ca}^{2+}\right]$ threshold for force production is much higher for the swimbladder than for the red fiber. Note the different time and $\left[\mathrm{Ca}^{2+}\right]$ scales. Based on Reference 4.

interpreted as a threefold higher $\mathrm{k}_{\text {off }}$ in swimbladder TNC $\left(345 \mathrm{~s}^{-1}\right)$ as the on-rate $\left(\mathrm{k}_{\mathrm{on}}\right)$ is fixed by diffusion. With this higher $\mathrm{k}_{\mathrm{off}}$, the rate of troponin deactivation is no longer limiting (Figure 3 in Reference 4).

The final requirement for force to drop quickly following the dissociation of $\mathrm{Ca}^{2+}$ from troponin is a fast cross-bridge detachment rate (Figure 1, step 6). The maximum velocity of shortening $\left(\mathrm{V}_{\max }\right)$, thought to be determined by the crossbridge detachment rate, showed a systematic increase in $\mathrm{V}_{\max }$ in different fibers with increasing twitch speed: The $\mathrm{V}_{\max }$ of the swimbladder muscle $\left(\sim 12 \mathrm{ML} \mathrm{s}^{-1}\right)$ is exceptionally fast (5- and 2.5-fold faster than toadfish red and white muscle, respectively) (Figure 5). Even more striking is the systematic 50-fold increase in the cross-bridge detachment rate constant, $g$ (Table 1) (23). The cross-bridge attachment rate constant $(f)$ and $g$ were calculated from measurements of steadystate relative stiffness and cross-bridge ATP utilization per myosin head (isometric ATP utilization/myosin heavy chain concentration). We found that $f$ increased 23 -fold between the red and white fibers and then remained fairly constant between the fast-twitch and superfast-twitch muscles (approximately $15 \mathrm{~s}^{-1}$ ). Similarly, $g$ increased approximately 3-fold between the slow-twitch red and the fast-twitch white muscles. However, between the fast-twitch white muscle and the superfasttwitch swimbladder, $g$ increased another 10 -fold to an extraordinary $108 \mathrm{~s}^{-1}$, by far the fastest ever measured. By comparison, the best-studied mammalian fiber type, the fast-twitch psoas fiber of rabbit, has a $g$ of only $2 \mathrm{~s}^{-1}$ (24). This fast $g$ appears necessary to enable the rapid relaxation observed (see below) (25).

In short, we found that at $15^{\circ} \mathrm{C}$ the swimbladder muscle had $(a)$ the fastest $\mathrm{Ca}^{2+}$ transient ever measured, $(b)$ the most right-shifted force versus $\left[\mathrm{Ca}^{2+}\right]$ curve 


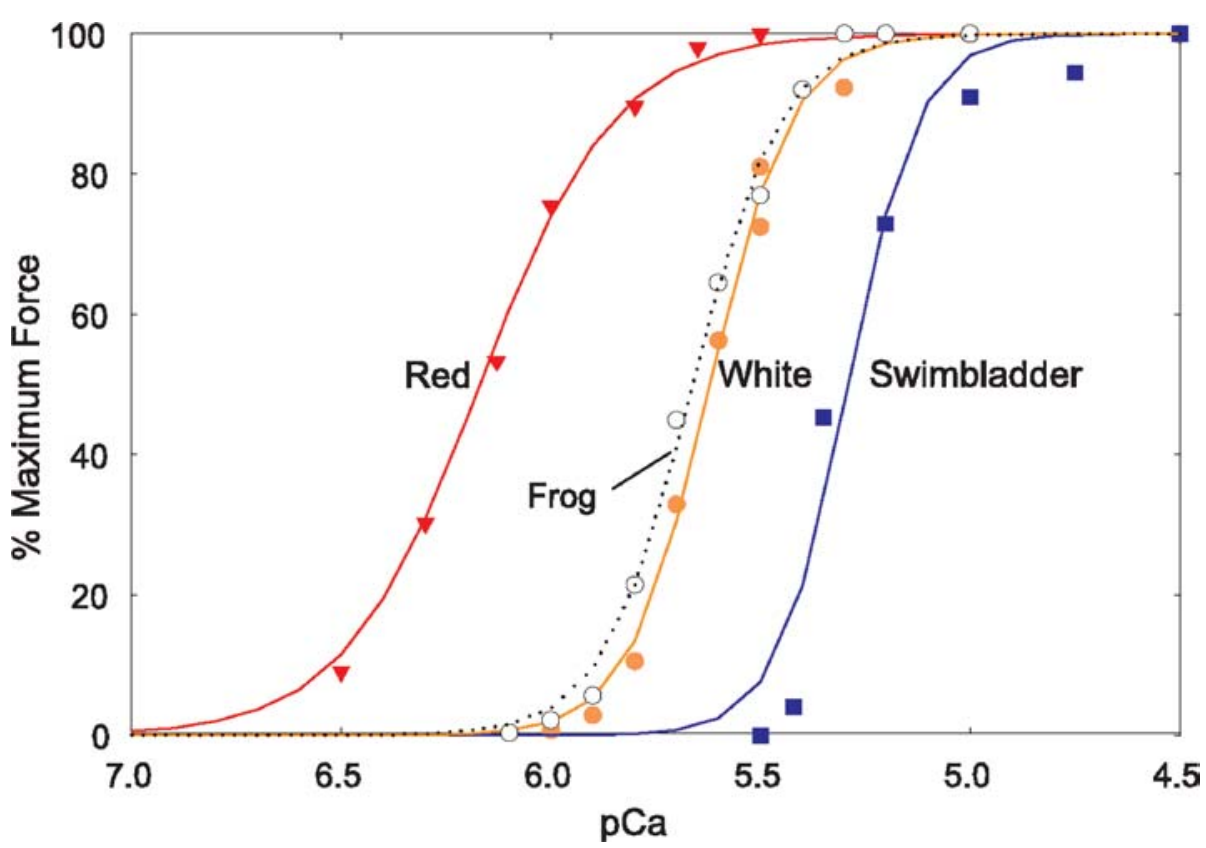

Figure 4 Force-pCa relationship for three muscle fiber types in toadfish (red fiber, red; white fiber, orange; swimbladder fiber, blue). A frog (Rana temporaria) fiber (dotted black line) is shown for comparison. The force from swimbladder fibers rose more sharply than the fitted curve at forces below $50 \%$ and more gradually than the fitted curve at forces above $80 \%$. Based on Reference 4.

(interpreted as the fastest $\mathrm{k}_{\mathrm{off}}$ ), and (c) the fastest detachment rate constant ever measured. This suggests that all three rate processes are important in setting the kinetics of this superfast fiber.

Further analysis of the $\mathrm{Ca}^{2+}$ transient and cross-bridge kinetics suggests that the process that ultimately limits relaxation rate may differ between fiber types. Figure 6 compares the detachment rate constant $g$ with the relaxation rate of intact muscle as twitch force falls from $95 \%$ to $80 \%$ of maximum tension [i.e., within this range, the fiber is thought to remain isometric, and the decline in force is not sped up artifactually by the collapsing sarcomere structure (21)]. There is a remarkable concordance between $g$ and the relaxation rate for the swimbladder muscle $\left(108 \mathrm{~s}^{-1}\right.$ versus $\left.104 \mathrm{~s}^{-1}\right)$ and for white muscle $\left(10.3 \mathrm{~s}^{-1}\right.$ versus $\left.10.6 \mathrm{~s}^{-1}\right)$. Furthermore, at the point of the twitch at which force had fallen below $95 \%$, the free $\left[\mathrm{Ca}^{2+}\right]$ had already dropped below the threshold level for force generation and thus could not be limiting relaxation. Hence, for white and swimbladder muscles, between which speed varies $\sim 10$-fold, we conclude it is likely that $g$ limits the speed of muscle relaxation. (However, as $\mathrm{k}_{\text {off }}$ of TNC has not been measured, we cannot discount the possibility that it may have contributed as well.) By contrast, red 


\subsection{ROME}

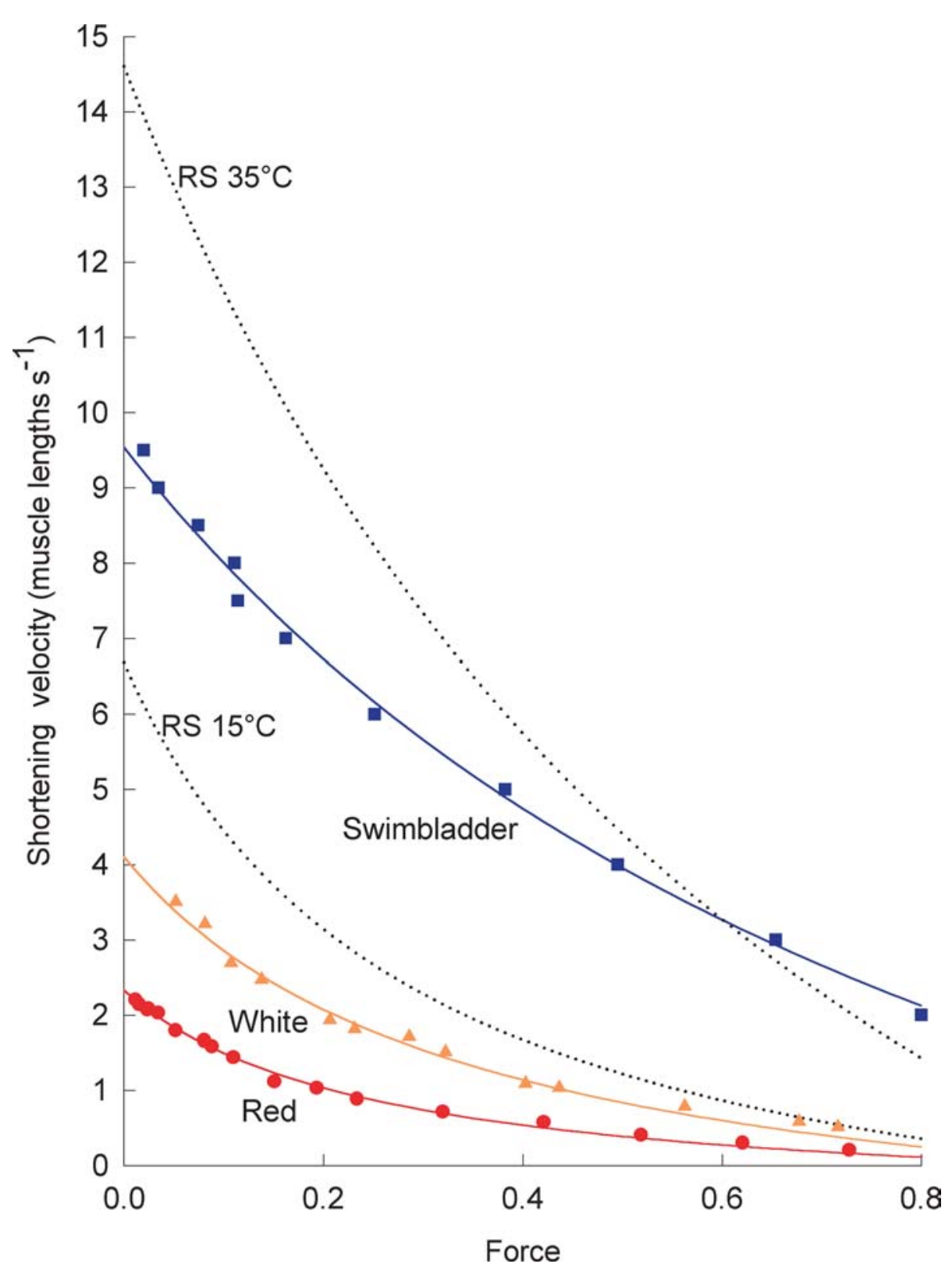

Figure 5 Force-velocity curves of toadfish and rattlesnake shaker fibers. The force-velocity curves of the toadfish red (red) and white (orange) and swimbladder fibers (blue) are shown with solid symbols and lines. The swimbladder $\mathrm{V}_{\max }\left(12\right.$ muscle lengths $\left.\mathrm{s}^{-1}\right)$ was determined from the slack test, and its force-velocity curve is shown only for comparison. The forcevelocity curves of the rattlesnake shaker fibers $(R S)$ are shown at $16^{\circ} \mathrm{C}$ and $35^{\circ} \mathrm{C}$ with dotted black curves. Based on Reference 4. 

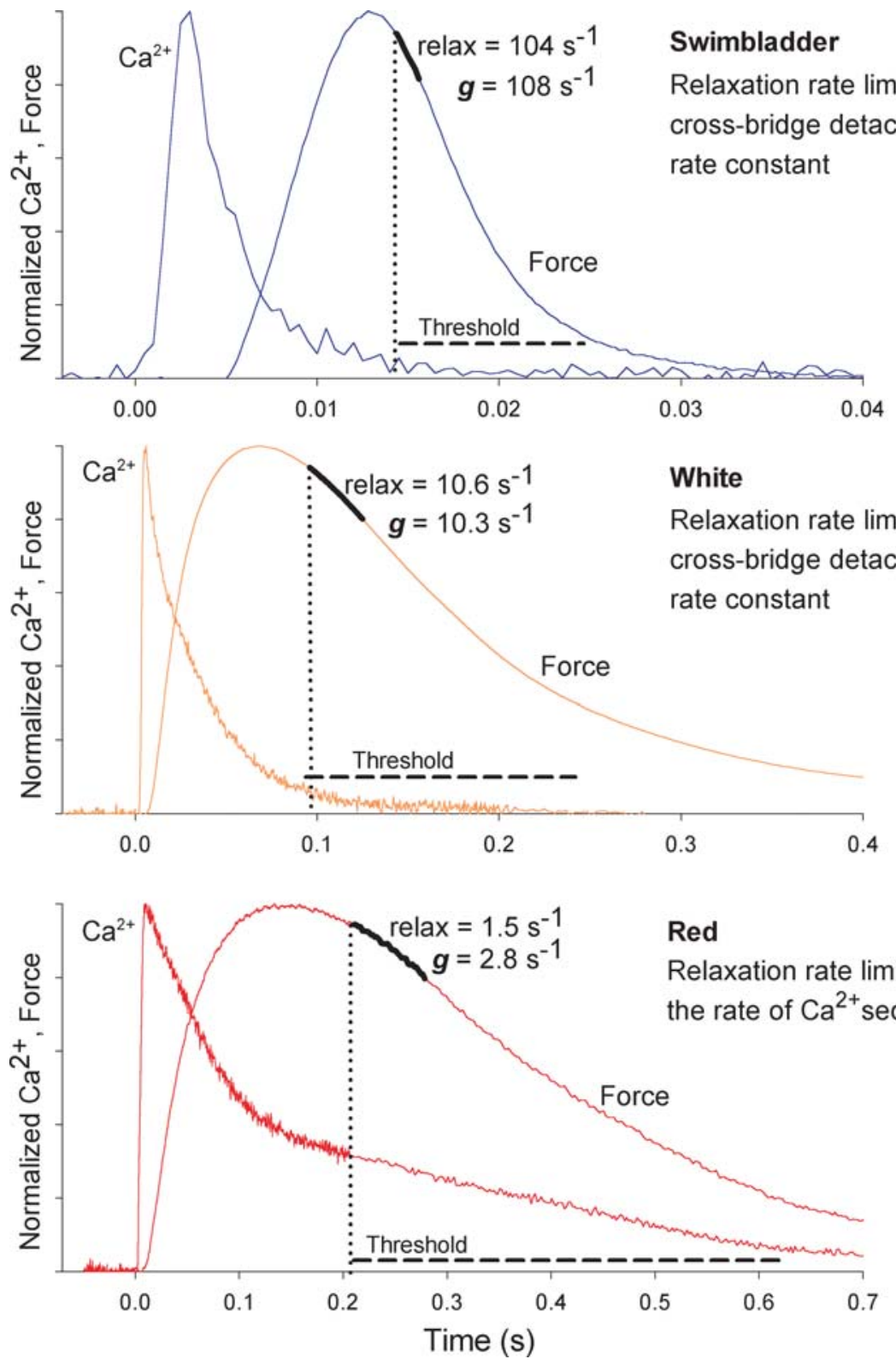

Figure 6 Comparison of muscle relaxation and the detachment rate constant $g$. For each muscle fiber (swimbladder, top; white, middle; red, bottom), the normalized $\mathrm{Ca}^{2+}$ transient and force are shown. Relaxation rate was calculated over the time when force was reduced from 95 to $80 \%$ of isometric force (thick black trace). The threshold $\mathrm{Ca}^{2+}$ for force generation determined from force-pCa (i.e., Figure 4) is denoted with a dashed horizontal line. Based on Reference 23 . 
muscle yields a different result. The value of $g\left(2.8 \mathrm{~s}^{-1}\right)$ was substantially faster than the initial relaxation rate $\left(1.5 \mathrm{~s}^{-1}\right)$. Furthermore, the myoplasmic $\left[\mathrm{Ca}^{2+}\right]$, although falling, remained above threshold during much of the decline in force (Figure 6). This suggests that, in red muscle, $\mathrm{Ca}^{2+}$ reuptake may be the rate-limiting step in relaxation.

It is important to note that although only one step appears to be limiting in each fiber type, all three adaptations are needed for high speed. For instance, a muscle with a $g$ of the swimbladder muscle and $\mathrm{Ca}^{2+}$ transient of white muscle would relax slowly (now $\mathrm{Ca}^{2+}$ reuptake would become rate limiting).

\section{Trading Force for Speed}

Measurements of cross-bridge kinetics have elucidated another remarkable specialization. In locomotory muscle, $f \gg g$, and thus the number of attached crossbridges [proportional to $f /(f+g)$ ] is high. In the red and white muscles, this calculation suggests that 60-70\% of the cross-bridges are attached during isometric contraction. In the swimbladder muscle, however, because such a high $g$ is required for rapid relaxation, $g \gg f$, and thus there should have been few (approximately $1 / 5$ that of locomotory muscle) attached cross-bridges. This observation suggests that these muscles would generate very low forces, which they do. Swimbladder muscle generates only approximately $1 / 20$ of the force of normal locomotory muscle (Table 1). Hence in superfast fibers there is a tradeoff of force for speed! This may represent a new design rule with significant implications for other very fast muscles (e.g., mammalian eye muscles). Although most of the reduction in force is due to cross-bridge kinetics, some is attributable to the fact that myofibrils make up only $\sim 50 \%$ of the cell volume (most of the remainder is taken up by a large SR) (18).

\section{The Downside of Speed: Mutually Exclusive Designs}

It is generally thought that, although fast-twitch muscle can generate more power than can slow-twitch muscle at any given velocity (based on generating more force at any given velocity), animals must also have slow-twitch muscles because slowtwitch muscles can generate power more efficiently at low shortening velocities (6). The low force generated by the swimbladder muscle led us to reevaluate this concept (14). We performed optimized workloop experiments in which the muscle was driven under sinusoidal length changes of various magnitudes and frequencies while the duration and phase of the stimulus were adjusted to obtain maximum power output (13). Figure 7 shows that red and white muscles cannot generate power above 2 and $12 \mathrm{~Hz}$, respectively. This result is expected on the basis of the slow cross-bridge and $\mathrm{Ca}^{2+}$ kinetics of these muscle types. However, we also found that the swimbladder muscle could not generate the power at the low frequencies required to drive swimming. Because of low forces, the mass-specific power generated by the swimbladder muscle at the low frequencies toadfish use for swimming $(0.8-4 \mathrm{~Hz})$ is a small fraction of that generated by the swimming muscles (i.e., $1 / 6$ 


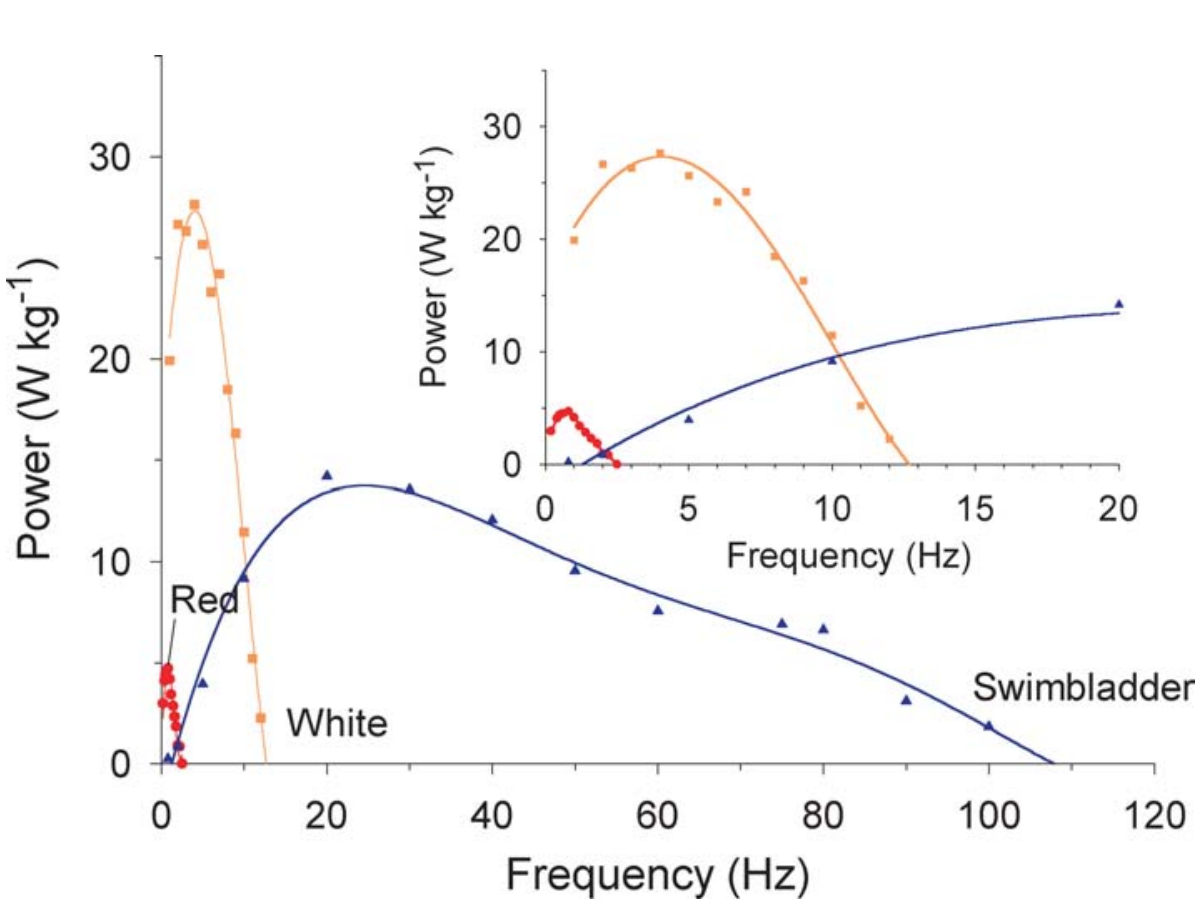

Figure 7 A plot of red muscle (red), white muscle (orange), and swimbladder muscle (blue) mean power output $\left(\mathrm{W} \mathrm{kg}^{-1}\right.$ ) versus cycle frequency $(\mathrm{Hz})$. Values were determined from optimized workloop experiments. Based on Reference 14.

and $1 / 20$ of that generated by white and red muscles, respectively). To generate the same total power required for swimming, the volume of the swimbladder muscle would have to be 6 -fold and 20-fold greater than that of white and red muscles, respectively, and simply could not fit into the fish! Hence, the different fiber types in toadfish have mutually exclusive designs and the locomotory red and white fibers can operate only at low frequencies, whereas the swimbladder muscle can operate effectively only at high frequencies. Thus the modifications made for speed in the swimbladder muscle are so extreme that it can no longer perform the function of powering swimming but is highly specialized for working at high frequencies.

\section{Quantitative Energetics of Swimbladder Muscle: Superfast Contraction Without Superfast Energetics}

There is a well-accepted relationship between steady-state ATP usage and the twitch speed of muscle (26). As the twitch speed of the muscle increases, so must the kinetics of the ATP-utilizing cross-bridges and SR-Ca ${ }^{2+}$ pumps, resulting in an increase in the steady-state rate of ATP utilization. We hypothesized that, because of the great twitch speed of swimbladder muscle, it should use ATP extraordinarily 
quickly. We measured the energetics of swimbladder muscle (i.e., the total rate at which skinned fibers utilized ATP). Surprisingly, despite performing twitches eight times faster than did frog fast-twitch fibers, the swimbladder did not use ATP any faster than did frog muscle fibers during steady-state contractions.

Because the overall rate of ATP usage by fibers is low, ATP utilization by cross-bridges and by $\mathrm{Ca}^{2+}$ pumps must both be low. We used standard partitioning techniques (i.e., knocking out the $\mathrm{Ca}^{2+}$ pumps as discussed in Reference 27) and also exploited the right-shifted force-pCa curve to measure SR-Ca ${ }^{2+}$ ATP utilization directly (i.e., at pCa below which force generation starts) to partition and measure directly the rate of ATP usage by the cross-bridges and SR-Ca ${ }^{2+}$ pumps (28). The means by which the swimbladder achieves the superfast $g$ needed for rapid relaxation with a modest ATP utilization per myosin head can be understood by the mechanism described above: The swimbladder muscle has very few attached cross-bridges at any one time $[=f /(f+g)]$; thus the cross-bridge cycling rate (ATPase $=$ number of attached bridges $* g$ ) is modest. However, the means by which the swimbladder muscle could have a superfast $\mathrm{Ca}^{2+}$ transient with a modest $\mathrm{Ca}^{2+}$ pumping rate remains a puzzle.

\section{CALCIUM CYCLING IN VIVO}

\section{A Simple Model of Calcium Movement: Quantitative Neuroethology and Quantitative Biochemistry}

To be able to develop an expectation of the $\mathrm{Ca}^{2+}$ fluxes during calling, one has to know the biomechanics of the call as well as the concentrations of constituent proteins in toadfish muscle. If we assume that the amount of $\mathrm{Ca}^{2+}$ released and taken up during every contraction is equal to that which just saturates troponin binding sites, then the precise TNC concentration must be known to predict $\mathrm{Ca}^{2+}$ flux. Using refined approaches (29), we found that the TNC concentration in swimbladder muscle is only $35 \mu$ moles per $\mathrm{kg}$ muscle. ${ }^{1}$ Hence swimbladder muscle has approximately $70 \mu \mathrm{mol} \mathrm{kg} \mathrm{kg}^{-1}$ of $\mathrm{Ca}^{2+}$ binding sites. Thus to saturate and desaturate TNC, $70 \mu \mathrm{mol} \mathrm{kg} \mathrm{kg}^{-1}$ of $\mathrm{Ca}^{2+}$ would need to be released (and pumped back into the SR) during each twitch.

Toadfish calls range from $\sim 80 \mathrm{~Hz}$ at low temperatures to $\sim 250 \mathrm{~Hz}$ at high temperatures (30). To obtain a more precise understanding of what the muscle must do requires further information on the number and frequencies of the sound pulses that comprise the call. Using hydrophones we recorded and analyzed the sound pulses (31) and found the calls could be divided temporally into two phases. Phase II represents the majority of the call and is characterized by extremely regular sound pulses with interpulse intervals of a constant value (Figure 8). By contrast,

\footnotetext{
${ }^{1}$ Although many authors (17) provide concentrations in terms of muscle water, we report values for the total muscle mass.
} 

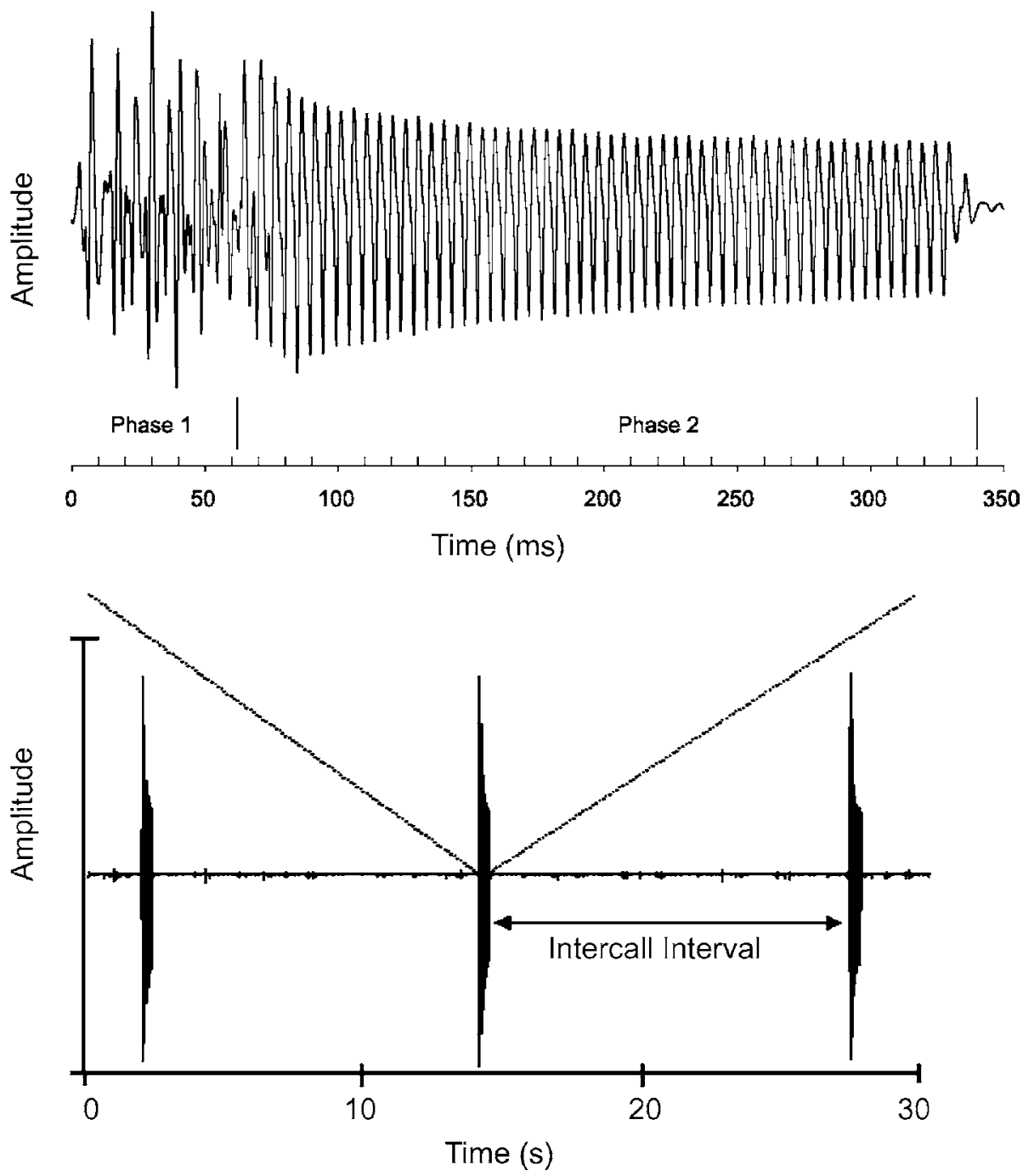

Figure 8 The boatwhistle mating call of toadfish. The bottom trace shows calls over a slow time base. Note that the calls are low duty cycle and that there can be long intercall intervals that appear to be obligatory. The upper trace shows an expanded view of one call. Whereas the first short portion of the call (Phase I) is irregular, the majority of the call (Phase II) is very regular. Based on Reference 31 . 
Phase I represents the short, initial portion of the call, when interpulse intervals are more variable. Whether Phase I represents the motor pattern with which the swimbladder is driven or is an emergent property of the whole system is unclear. We focused on Phase II because of its regularity. From this work, we determined the necessary pattern with which to stimulate the muscle. We concentrated our work at $15^{\circ} \mathrm{C}$, used 80 and $100 \mathrm{~Hz}$ to simulate the muscle stimulation frequency, and used a call duration of $400 \mathrm{~ms}$.

Hence, if during each twitch, $70 \mu \mathrm{mol} \mathrm{kg}{ }^{-1}$ of $\mathrm{Ca}^{2+}$ is released, saturates troponin, and then is pumped back into the SR before the next stimulus, then calling at $100 \mathrm{~Hz}$ would require a steady state pumping rate of $7 \mathrm{mmol}$ of $\mathrm{Ca}^{2+} \mathrm{kg}^{-1}$ $\mathrm{s}^{-1}$. If we assume a stoichiometry of two $\mathrm{Ca}^{2+}$ per ATP (32), our measurement of ATPase rate associated with $\mathrm{Ca}^{2+}$ pumping $\left(1 \mathrm{mmol} \mathrm{kg}^{-1} \mathrm{~s}^{-1}\right)$ is equivalent to a $\mathrm{Ca}^{2+}$ pumping rate ${ }^{2}$ of $2 \mathrm{mmol} \mathrm{kg}^{-1} \mathrm{~s}^{-1}$ (Figure 9). This value is three- to fourfold slower than that which appears necessary for the swimbladder muscle to twitch continuously at the high frequencies $(100 \mathrm{~Hz})$ used for calling at $15^{\circ} \mathrm{C}$. Hence the SR-Ca ${ }^{2+}$ pumps simply cannot keep up in real time. So how does swimbladder muscle generate rapid $\mathrm{Ca}^{2+}$ transients with a relatively low $\mathrm{Ca}^{2+}$ pumping rate?

\section{Two Mechanisms and the Need for New Approaches}

The classical description of the activation-relaxation process is that the SR releases sufficient $\mathrm{Ca}^{2+}$ to saturate troponin (or considerably more should there be additional buffers such as PARV), and during the relaxation process all the $\mathrm{Ca}^{2+}$ is pumped back into the SR. Two mechanisms can explain the apparent paradox we describe above:

Mechanism 1: During calling there may not be complete saturation and desaturation of troponin during each twitch; rather, the troponin saturation level may rise slightly and fall slightly while operating on a steep portion of the force-versus-troponin saturation curve. This would provide an oscillation of force with relatively little exchange of $\mathrm{Ca}^{2+}$, and thus considerable reduction in the average $\mathrm{Ca}^{2+}$ release and reuptake per stimulus. Evidence to support this mechanism is the observation that, when held isometrically and stimulated at $100 \mathrm{~Hz}$, the swimbladder muscles do not fully relax between stimuli.

Mechanism 2: Most of the $\mathrm{Ca}^{2+}$ released during a call temporarily binds to PARV and is released from PARV and pumped back into the SR during the long intercall interval (i.e., only after the muscle has relaxed).

To test Mechanism 1, we needed to know how much $\mathrm{Ca}^{2+}$ is released per twitch in an intact muscle. However, there was no technique available to measure

\footnotetext{
${ }^{2}$ An approximate value was found (28) prior to the development of new techniques utilizing $N$-benzyl- $p$-toluene sulfonoaminde. $N$-benzyl- $p$-toluene sulfonoaminde usage permitted a more accurate measurement of the maximum rate (Figure 9) (33).
} 


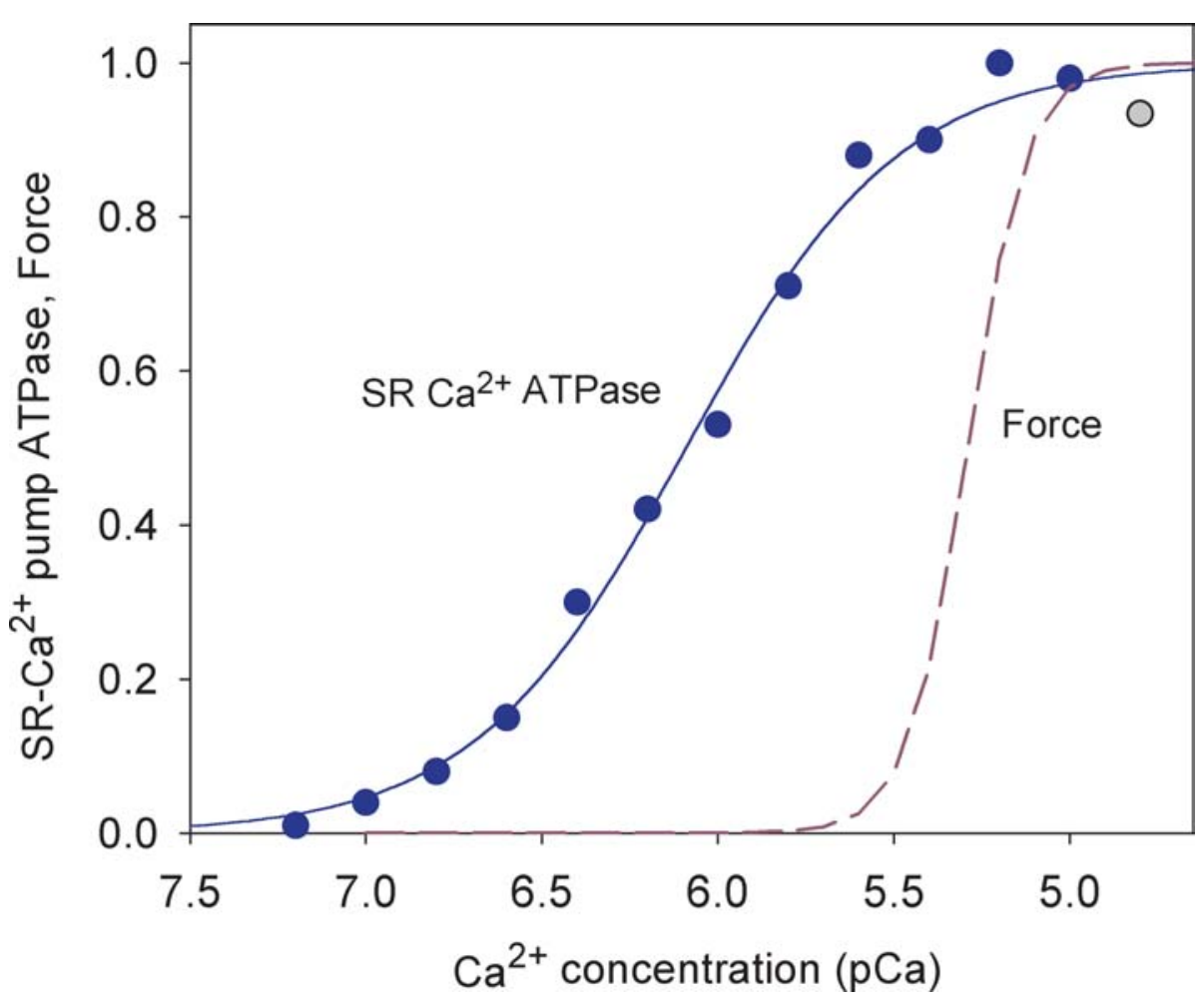

Figure 9 SR-Ca ${ }^{2+}$-pump ATP utilization as a function of free $\left[\mathrm{Ca}^{2+}\right]$ in skinned fibers. All experiments were performed in the presence of $25 \mu \mathrm{M} \mathrm{N}$-benzyl-p-toluene sulfonoaminde, which removed more than $95 \%$ of the cross-bridge ATP utilization and $5 \mathrm{mM}$ caffeine to prevent back-inhibition of the SR-Ca ${ }^{2+}$ pumps. ATP utilization (blue) reached a maximum at approximately pCa 5.2 and then declined slightly with higher $\left[\mathrm{Ca}^{2+}\right]$ (shown as gray; not included in curve fit). Force-pCa plot (purple) from another swimbladder experiment is added for comparison. Based on Reference 33.

this. Although it is often assumed that the $\mathrm{Ca}^{2+}$ transient describes the amount of $\mathrm{Ca}^{2+}$ released, such an assumption blurs a crucial distinction between free $\left[\mathrm{Ca}^{2+}\right]$ and total $\mathrm{Ca}^{2+} . \mathrm{Ca}^{2+}$ transient durations provide information about the speed of changes in free $\left[\mathrm{Ca}^{2+}\right]$; however, they do not by themselves provide information about the magnitude and time course of the total amount of $\mathrm{Ca}^{2+}$ released, its reuptake, or its binding to different proteins in the cell. The vast majority of $\mathrm{Ca}^{2+}$ released in a muscle cell is bound during contraction (i.e., to TNC and PARV), and there are significant kinetic delays between $(a)$ the drop of free $\left[\mathrm{Ca}^{2+}\right]$ and $(b)$ $\mathrm{Ca}^{2+}$ unbinding from PARV and being pumped back into the SR (34). Hence it is difficult to equate the kinetics of the $\mathrm{Ca}^{2+}$ transient (or muscle relaxation) with the amount and time course of $\mathrm{Ca}^{2+}$ release and reuptake $(17,33,35)$. 
Thus, we had to develop new techniques for measuring the amounts of $\mathrm{Ca}^{2+}$ released and pumped back into the SR per twitch. New techniques were also necessary to test Mechanism 2 (see below). It became apparent that in solving the riddle posed by the swimbladder muscle, we had to answer general questions about calcium cycling and PARV function. Hence, here we depart from discussing just superfast muscle and explain in more detail the approach and findings, which are generalizable to all muscles.

The new approaches to answering these questions are based on two facts: First, $\mathrm{Ca}^{2+}$ pumping requires the utilization of ATP in a fixed stoichiometry of two $\mathrm{Ca}^{2+}$ per ATP. Thus the total amount of ATP utilized by the SR-Ca ${ }^{2+}$ pumps can be used as a proxy for the amount of $\mathrm{Ca}^{2+}$ pumped. Second, we have been able to show that a new myosin II inhibitor, $N$-benzyl- $p$-toluene sulfonoaminde (BTS), can be used to knock out cross-bridge ATPase (as well as cross-bridge force) and thereby unmask SR-Ca ${ }^{2+}$ pump ATP utilization. Although highly effective SR-Ca ${ }^{2+}$ pump inhibitors [e.g., 2,5-di-(tert-butyl)-1,4-benzohydroquinone (TBQ)] have been available for some time, there has been a strong need for a specific and potent cross-bridge inhibitor that does not affect $\mathrm{Ca}^{2+}$ pumping rate. Using combinatorial chemistry and high throughput screening, Mitchison and colleagues (36) found that BTS appeared to block myosin ATPase from fast-twitch fibers and knocked out force generation while seeming to have little effect on the $\mathrm{Ca}^{2+}$ transient in frog fibers.

We recognized that BTS could be used not only to distinguish between the two mechanisms but more broadly to help answer a series of questions that had not been accessible by previously available techniques. We performed a series of experiments to determine $(a)$ whether BTS could completely block the cross-bridge ATPase and $(b)$ at that concentration does it affect SR-Ca ${ }^{2+}$ pump ATPase? First, we found that at $25 \mu \mathrm{M}$, BTS reduced the cross-bridge ATPase to only $3 \%$ of its original value, and force fell to a very low value indistinguishable from zero. Second, we then exploited the right-shifted force-pCa relationship in swimbladder muscle, which permitted us to measure $\mathrm{SR}-\mathrm{Ca}^{2+}$ ATP utilization both with and without a cross-bridge blocker up to $\left[\mathrm{Ca}^{2+}\right]$ of pCa 5.8 (i.e., at lower $\left[\mathrm{Ca}^{2+}\right]$, the cross-bridges do not generate force or utilize ATP). At $25 \mu \mathrm{M}$, the BTS had no apparent effect on the SR-Ca ${ }^{2+}$ pump ATPase. ${ }^{3}$ Hence, we were then able to measure SR-Ca ${ }^{2+}$ pump ATPase over a wide range of $\left[\mathrm{Ca}^{2+}\right]$. We found that the SR-Ca ${ }^{2+}$ pump ATPase increased with increasing $\left[\mathrm{Ca}^{2+}\right]$ with a relatively low Hill coefficient $(\sim 1.45)$ and that the $50 \%$ pumping rate occurred at a $\left[\mathrm{Ca}^{2+}\right]$ of $\sim 0.83 \mu \mathrm{M}$ ( $\mathrm{pCa}=6.08)$. By using $\mathrm{SR}-\mathrm{Ca}^{2+}$ pumping as a proxy for $\mathrm{Ca}^{2+}$ pumping, we determined the maximal steady-state pumping rate of $2 \mathrm{mmol} \mathrm{kg}^{-1} \mathrm{~s}^{-1}$.

Most importantly, we found that BTS not only works on skinned fibers but also can be used in large intact bundles suitable for energetics. As in skinned fibers,

\footnotetext{
${ }^{3}$ Note that because of its right-shifted force-pCa curve, the swimbladder is the only muscle known in which a direct test of BTS could have been performed. In all other muscles, cross-bridge ATPase completely overlaps SR-Ca ${ }^{2+}$ pump ATPase.
} 
exposure of intact bundles to $25 \mu \mathrm{M}$ BTS knocks out more than $95 \%$ of the crossbridge ATP utilization, thereby unmasking the SR-Ca ${ }^{2+}$ pump ATP utilization. The other important property of intact muscle is that, because it is a closed system, if a muscle is given sufficient time to recover from contraction, all of the $\mathrm{Ca}^{2+}$ that was released will eventually be pumped back into the SR. Thus $\mathrm{Ca}^{2+}$ pumped equals $\mathrm{Ca}^{2+}$ released.

We used recovery oxygen consumption experiments to measure the high-energy phosphate breakdown, enabling us to determine how much $\mathrm{Ca}^{2+}$ was released per twitch (37). Preliminary evidence shows that in the first stimulus, $240 \mu \mathrm{mol} \mathrm{kg}{ }^{-1}$ (or three and one-half times the amount of TNC sites) is released, but this amount declines dramatically with increasing stimuli. After approximately the tenth twitch, $\mathrm{Ca}^{2+}$ release declines to a level $\left(48 \mu \mathrm{mol} \mathrm{kg}{ }^{-1}\right)$ below that required to saturate and desaturate troponin. This observation provides strong evidence for the reduction in $\mathrm{Ca}^{2+}$ release during calling.

Two processes are known to modulate the magnitude of $\mathrm{Ca}^{2+}$ release. First, Chandler and colleagues (38) showed in cut frog fibers (in which the amount of $\mathrm{Ca}^{2+}$ in the SR could be manipulated by changing $\left[\mathrm{Ca}^{2+}\right]$ in the bathing solution) that the absolute quantity of $\mathrm{Ca}^{2+}$ release per stimulus depends on the amount of $\mathrm{Ca}^{2+}$ remaining in the SR (39). In the swimbladder, the amount of $\mathrm{Ca}^{2+}$ in the SR should decline over the period of the call (because much of the $\mathrm{Ca}^{2+}$ may be bound to PARV in the myoplasm). Thus it is critical to know how much $\mathrm{Ca}^{2+}$ is left in the SR prior to any given stimulus. By the tenth stimulus, the $\mathrm{Ca}^{2+}$ release per stimulus had declined fivefold, even though preliminary results suggest that only $20 \%$ of total SR-Ca ${ }^{2+}$ had been released. Hence, dwindling SR $\mathrm{Ca}^{2+}$ levels play only a minor role in the decline of $\mathrm{Ca}^{2+}$ released per stimulus.

The second process that modulates $\mathrm{Ca}^{2+}$ release is $\mathrm{Ca}^{2+}$ release channel inactivation. Paired stimuli experiments have shown that the size of the $\mathrm{Ca}^{2+}$ transient in intact fibers (and the amount of $\mathrm{Ca}^{2+}$ release in cut fibers) declines dramatically in the second stimulus if it is given in close succession to the first (39). It is likely that inactivation plays a large part in the reduction of $\mathrm{Ca}^{2+}$ release from swimbladder muscle. Hollingworth \& Baylor (40) showed that, similar to frog muscle, there is considerable inactivation in swimbladder muscle with a time constant of $25 \mathrm{~ms}$.

\section{The Role of Parvalbumin}

Although the amount of $\mathrm{Ca}^{2+}$ released per twitch drops below that needed to saturate the troponin, this is not quantitatively large enough to provide the observed 3.5 -fold shortfall in the rate of $\mathrm{Ca}^{2+}$ pumping. By exclusion, this suggests that PARV must play an important role. $\mathrm{Ca}^{2+}$ sequestration is equal to the sum of that associated with PARV and that associated with the SR-Ca ${ }^{2+}$ pumps. The quantitative role of PARV in setting the $\mathrm{Ca}^{2+}$ transient and twitch duration, however, is controversial. Because PARV is found only in fast muscles, it is generally associated with speed. In fact, there have been a number of reports in which twitch speed is positively correlated with PARV concentrations $(41,42)$, and there are several 
direct demonstrations of PARV's ability to speed relaxation $(43,44)$. Thus, one interpretation is that high PARV concentration is a requisite of fast contraction and hence is a major determinant of the $\mathrm{Ca}^{2+}$ transient. Seemingly in confirmation of this notion, toadfish swimbladder muscle, the fastest-contracting vertebrate muscle, also has the highest concentration of PARV measured (Table 1) (18).

Although it is clear that PARV can accelerate the $\mathrm{Ca}^{2+}$ transient and relaxation in some fiber types, kinetic and binding measurements suggest PARV may not be as effective in accelerating the $\mathrm{Ca}^{2+}$ transient in superfast muscle like the swimbladder. Most $\mathrm{Ca}^{2+}$ binding sites on PARV are thought to be filled by $\mathrm{Mg}^{2+}$ in the resting muscle $(17,21,35,45)$. Protecting these sites is a necessity to prevent PARV from competing with TNC during $\mathrm{Ca}^{2+}$ release. Although $\mathrm{Ca}^{2+}$ has a 10,000-fold higher affinity and can outcompete $\mathrm{Mg}^{2+}$ for PARV binding sites, the absolute rate at which sites become available in the muscle depends on the product of the kinetic off-rate of $\mathrm{Mg}^{2+}$ from PARV, which is slow $\left[2 \mathrm{~s}^{-1}\right.$ at $\left.10^{\circ} \mathrm{C}(21,45)\right]$, and [PARV]. This would suggest that the potential effectiveness of PARV may diminish as the speed of the $\mathrm{Ca}^{2+}$ transient increases.

Another unknown is the function PARV plays during normal activity. As noted above, PARV increases the speed of muscle relaxation for short stimuli, but what functional advantage does this bestow on the animal during normal activity? For instance, it is generally assumed that PARV would be useless to muscles involved in sustained activities because it would quickly become saturated $(21,45)$. Consistent with this assumption, PARV is not found in cardiac muscle and very little is found in slow-twitch muscle (which is the most-often recruited). However, Metzger and colleagues (44) found that the addition of PARV (by injection of cDNA) not only accelerates the relaxation rate in cardiac muscle but also improves cardiac function during normal continuous heart pumping. This surprising result underscores our incomplete understanding of PARV's in vivo function.

\section{Toward a Quantitative Measure of Parvalbumin Usage During In Vivo Function}

A measurement of $\mathrm{Ca}^{2+}$ binding of PARV during contraction in a well-defined, naturally occurring experimental system is necessary to understand the function of PARV. By using BTS and the ATP utilization by the SR- $\mathrm{Ca}^{2+}$ pumps as a proxy, we have been able to track the movements of $\mathrm{Ca}^{2+}$ onto and off PARV.

Toadfish call for many hours, which may suggest PARV would become quickly saturated, and hence ineffective at sequestering $\mathrm{Ca}^{2+}$. However, a more detailed examination of the calling pattern suggests that PARV could play a large role. Even though the toadfish can call for many hours, the duty cycle of the call [call duration/(call duration + intercall interval)] is small. A typical call is $400 \mathrm{~ms}$, but the intercall interval is $5-15 \mathrm{~s}$. Hence, the duty cycle is approximately $2.5-$ $7.5 \%$. Given this time course of calling (low duty cycle and long intercall interval) and the large [PARV], PARV could contribute significantly to the sequestration of $\mathrm{Ca}^{2+}$ during calling. During the actual call, much of the released $\mathrm{Ca}^{2+}$ could 
bind to PARV. This $\mathrm{Ca}^{2+}$ would be subsequently pumped back into the SR during the relatively long intercall intervals. Furthermore, the high concentration of $\mathrm{Ca}^{2+}$ binding sites associated with PARV ( $3 \mathrm{mM})(18)$ seems to be sufficient to sequester much of the $\mathrm{Ca}^{2+}$ released during a contraction. Electron microprobe studies on frog muscle (34) suggest that considerable $\mathrm{Ca}^{2+}$ can be left bound in the myoplasm at the point of relaxation and that this is sequestered during the postrelaxation phase accompanied by hydrolysis of ATP $(46,47)$. Hence, toadfish seem to have both the need and the opportunity to utilize PARV. Thus the swimbladder muscle represents a compelling model with which to examine the role of PARV during in vivo function.

We developed a method by which we can track $\mathrm{Ca}^{2+}$ unbinding from PARV. At the end of the 400-ms call, we anticipated that the PARV would be nearly saturated with $\mathrm{Ca}^{2+}$ and that during the intercall interval (i.e., postrelaxation), the $\mathrm{Ca}^{2+}$ would unbind from PARV and be pumped into the SR by the SR-Ca ${ }^{2+}$ pumps. Thus we can use the ATP breakdown by the SR-Ca ${ }^{2+}$ pumps during the intercall interval to assess the time course and magnitude of the $\mathrm{Ca}^{2+}$ unbinding from PARV (48).

Muscle bundles preincubated in BTS were stimulated for $400 \mathrm{~ms}$ (duration of calls), and some were frozen immediately after the muscle relaxed with a robotic muscle-freezing device. Other bundles were stimulated for the same $400 \mathrm{~ms}$; however, we delayed freezing them for $100-5000 \mathrm{~ms}$ following relaxation. To prevent high-energy phosphate regeneration during the interim, glycolysis was poisoned with iodoacetic acid, and oxidative phosphorylation was prevented by incubating the muscle bundles in nitrogen-saturated Ringers solution.

To obtain several duplicates at different time points, 20-25 experimental bundles and controls were necessary. Fish again represented a particularly good model because 20-30 bundles could be dissected from a single swimbladder. By contrast, such measurements in frogs would have required a minimum of 20-30 individuals. ${ }^{4}$

Under these conditions there was an increase in $\mathrm{Pi}$, a fall in $\mathrm{CrP}$, and little change in ATP. Because the Pi measurement was the most repeatable, we focused our analysis on those data. The ATP that was utilized during the 400-ms contraction was the difference between values from bundle stimulated for $400 \mathrm{~ms}$ (and then frozen immediately) and the resting Pi concentration obtained from unstimulated bundles. These preliminary data show that the amount of ATP used, and thus the amount of $\mathrm{Ca}^{2+}$ pumped during the call, was small. To determine the magnitude and time course of the postrelaxation ATP utilization, we subtracted the average value obtained from the muscle frozen immediately after relaxation from values obtained from muscle frozen at different times. Preliminary results show that between 1.5$2 \mathrm{mmol} \mathrm{kg}^{-1}$ of high-energy phosphate were broken down following relaxation. This greatly outweighed the amount of ATP broken down during contraction.

\footnotetext{
${ }^{4}$ Frogs exhibit a large interindividual variation, and the muscle from one leg must be used as a control for the experimental muscle on the other leg. Hence, one obtains only a single experimental datum per frog. In toadfish, four bundles serve as controls for all the rest.
} 
Thus approximately $80 \%$ of the ATP utilization by the $\mathrm{SR}^{-\mathrm{Ca}^{2+}}$ pumps occurs following relaxation. This represents a fundamentally different way of thinking about how muscle is turned on and off but supports our prediction of possible PARV function based on our quantitative analysis of SR-Ca ${ }^{2+}$ pumping.

Evidence is strong that the large postrelaxation SR-Ca ${ }^{2+}$ pump ATPase is due to $\mathrm{Ca}^{2+}$ coming off PARV and being pumped back into the SR:

1. The results of a sister set of experiments show that the magnitude of postrelaxation ATP utilization is saturable, which would be expected if it reflected a buffer of fixed size like PARV.

2. This magnitude is appropriate for PARV. Toadfish swimbladder has the highest PARV concentration ever measured $(1.5 \mathrm{mM})$, corresponding to $3-\mathrm{mM}$ $\mathrm{Ca}^{2+}$ binding sites. Assuming two $\mathrm{Ca}^{2+}$ pumped per ATP, our results are consistent with all of the $3-\mathrm{mM} \mathrm{Ca}^{2+}$ sites binding $\mathrm{Ca}^{2+}$ during the call, followed by the $\mathrm{Ca}^{2+}$ being pumped back into the SR.

3. The kinetics appear to be too fast for PARV. The rate constant we observed is $3 \mathrm{~s}^{-1}$, whereas the off-rate of $\mathrm{Ca}^{2+}$ from frog PARV is $1 \mathrm{~s}^{-1}$ (45). However, we found that toadfish possess different PARV isoforms. We have purified PARV from swimbladder, and preliminary results from stopped-flow kinetics on the predominant isoform in the same-size fish used in this experiment show a rate of approximately $3 \mathrm{~s}^{-1}$ (J. Davis, B.A. Tikunov, J. Rall, and L.C. Rome, personal communication).

4. Finally, the animal's calling behavior is consistent with this mechanism. It takes approximately 3-5 s for $\mathrm{Ca}^{2+}$ to be completely resequestered, and toadfish always leave $5 \mathrm{~s}$ between the end of one call and the beginning of the next.

Thus, by using this unique animal model, we have been able to track calcium cycling and PARV usage in muscle undergoing its natural stimulation pattern. We showed that two factors enable toadfish swimbladder muscle to power fast $\mathrm{Ca}^{2+}$ transients with moderate $\mathrm{Ca}^{2+}$ pumping: (a) reduced $\mathrm{Ca}^{2+}$ release per twitch and, more importantly, (b) PARV binding $\mathrm{Ca}^{2+}$ during the call (and slowly releasing it during the long intercall interval).

\section{THE STUDY OF SUPERFAST MUSCLES IN THE MIDSHIPMAN}

Midshipman (Porichthys notatus) calls for its mate by using its swimbladder muscle. The communication system as well as the ultrastructure of its muscle have been beautifully studied by Bass and colleagues (49). Males call at $\sim 100 \mathrm{~Hz}$ at $12-15^{\circ} \mathrm{C}$. Preliminary experiments show that the males' muscles have fast twitches (L.C. Rome, A.A. Klimov, B.A. Tikunov, and A.H. Bass, personal communication). Furthermore, they have a right-shifted force-pCa curve (neither the $\mathrm{Ca}^{2+}$ 
transient nor the cross-bridge detachment rate constant has been measured). Finally, we have found that, as in toadfish, the muscle generates very low forces. Although showing that the modifications made in the superfast muscle from another species are similar to those found in the toadfish is important to verify the necessity and generality of these traits, there are four additional reasons to study midshipman:

1. Unlike toadfish that call with a $2.5-7.5 \%$ duty cycle, midshipman call with a $100 \%$ duty cycle (i.e., they call continuously for hours at a time).

2. Unlike toadfish, which show only minor differences between male and female (18), midshipman exhibit profound sexual dimorphism in their swimbladder muscle (49). The Type 1 (calling) males have a large muscle ( $\sim 3-$ $7 \mathrm{~mm}$ thick) with a very high aerobic capacity (i.e., red in color). By contrast, the females, which do not call, have only a thin wisp of white muscle (several fibers thick).

3. Perhaps the most striking sexual dimorphism occurs at the ultrastructural level: In the calling males, the z-bands of the swimbladder muscle are $1-\mu \mathrm{m}$ thick or $\sim 20$ times longer than in other vertebrates. By contrast, the males' locomotory muscle as well as the z-band of the female swimbladder have normal thicknesses of $\sim 0.05 \mu \mathrm{m}$. Because the other myofilaments in the calling male have normal lengths, the resting sarcomere length in the swimbladder muscle is $3.2 \mu \mathrm{m}$, compared with $2.2 \mu \mathrm{m}$ for all other midshipman skeletal muscles.

4. The dimorphisms we discuss above appear to be based on function rather than just sex. Although the calling male (also called Type 1) has a different muscle ultrastructure than has the female, some male midshipman that do not call (Type 2) have exactly the same muscle structure as the female. These "sneaker males" stay in the vicinity of a calling male's nest and try to mate with the female that has been attracted by the Type 1 male's call (50).

Two questions must be answered about midshipman. First, how do they cycle $\mathrm{Ca}^{2+}$ without being able to use PARV as a temporary buffer? If no intercall interval exists, then PARV would become saturated quickly, and there would be no time period during which $\mathrm{Ca}^{2+}$ could unbind from PARV and be pumped back into the SR. Preliminary experiments show that the SR-Ca ${ }^{2+}$ pumping rate is no higher in the swimbladder of Type 1 males than it is in toadfish swimbladder (J. Marx, B.A. Tikunov, A.H. Bass, and L.C. Rome, personal communication). Second, what is the functional significance of the long z-bands in midshipman swimbladder muscle? We have hypothesized that, at a minimum, they act as an inert spacer (so that the muscle could span a given distance with fewer sarcomeres). As the z-bands do not contain cross-bridges or SR-Ca ${ }^{2+}$ pumps, they would not use ATP during contractions, which would result in an overall reduction in ATP usage. However, the long z-bands may form an elastic structure (51) that in some 
way permits the midshipman swimbladder to oscillate force with little exchange of $\mathrm{Ca}^{2+}$.

\section{TEMPERATURE EFFECTS: WHAT MAKES A FAST MUSCLE SUPERFAST?}

One interesting question regards the physiological, biochemical, and morphological criteria used to categorize a fast muscle as superfast. From a physiological/biomechanical viewpoint, superfast muscle must be able to perform mechanical work at high frequencies as measured by workloop experiments, and there is strong evidence that this requires fast kinetics of the three sequential mechanisms involved in relaxation. However, fast kinetics can be obtained in two ways: $(a)$ by altering the myosin and troponin isoforms and the quantity of SR pumps (as found in swimbladder) or (b) by simply raising the temperature. Temperature has a large effect on kinetic processes involved in muscle relaxation. At very low temperatures, SR-Ca ${ }^{2+}$ pumps have a $\mathrm{Q}_{10}$ of nearly 5, and $\mathrm{V}_{\max }$ (which is a manifestation of cross-bridge kinetics) has a $\mathrm{Q}_{10}$ of 3. Although these $\mathrm{Q}_{10} \mathrm{~s}$ moderate at higher temperatures, they are still large. This raises the question: Can a muscle that is only "fast" at low temperatures become "superfast" at high temperatures? As an example, at $35^{\circ} \mathrm{C}$ the rattlesnake shaker muscle's $\mathrm{Ca}^{2+}$ transient, $\mathrm{V}_{\max }$, and twitch are faster than those of the toadfish swimbladder at $15^{\circ} \mathrm{C}$, and it can generate mechanical power at frequencies exceeding $90 \mathrm{~Hz}$ (4). However, at $15^{\circ} \mathrm{C}$, compared to swimbladder, the shaker muscle ${ }^{5}$ has a 2-3-ms slower $\mathrm{Ca}^{2+}$ transient, a considerably slower $\mathrm{V}_{\max }$, and a much slower twitch and can generate mechanical power up to only approximately $30 \mathrm{~Hz}$. Although, based solely on the kinetics, the results from $35^{\circ} \mathrm{C}$ suggest that the shaker muscle is certainly a superfast muscle, the values obtained at $15^{\circ} \mathrm{C}$ are within the realm of the fastest locomotory muscles at high temperatures (e.g., hummingbird at $40^{\circ} \mathrm{C}$ ). However, taking into account that $30 \mathrm{~Hz}$ is obtained at $15^{\circ} \mathrm{C}$ puts the shaker muscle into the superfast category. Furthermore, all superfast muscle appear to have high SR volumes ( $30 \%)$ and an isoform of myosin different from that of the locomotory muscles. Therefore, from a morphological and biochemical viewpoint, the shaker muscle would be categorized as superfast $(25,52)$.

As superfast muscles have probably evolved multiple times [perhaps even in $\operatorname{birds}^{6}(53)$ for vocalization], it is unlikely that each muscle has precisely the

\footnotetext{
${ }^{5}$ Maximum isometric force was not measured in these rattlesnake shaker muscles. An indication of little shift in the force-pCa curve at $15^{\circ} \mathrm{C}$ was also found.

${ }^{6}$ The criteria used to categorize the bird muscle as superfast (it did not tetanize until stimulated at more than $200 \mathrm{~Hz}$, and twitch force was very low) are not sufficient to conclude that this muscle is superfast (i.e., this property could be the result of the membrane properties). It must be demonstrated that the muscle is capable of generating power at high frequencies by the workloop technique.
} 
same changes in myosin or troponin. Because we believe we have identified three functional traits that are necessary for power production at high frequencies, understanding the evolution of these traits (all three of which appear necessary) is a fascinating area for future research on superfast muscles.

\section{CONCLUSION}

From one viewpoint, the work reviewed here provides information about the function of superfast muscles, but in a larger sense it provides both an improved understanding of muscle physiology in general and a paradigm for studying it. This approach represents a confluence of cellular and molecular physiology, biophysics, integrative physiology, quantitative physiology, quantitative biochemistry, quantitative ultrastructure, and modeling as well as biomechanics and neuroethology. All these approaches have contributed novel insights to our understanding. First, integrative physiology is important because it is through the process of integration that gaps in our understanding become apparent. Integrating function frequently reveals crucial experiments have never been performed and also provides the motivation for performing them. Integration is not only important across higher levels of organization but also necessary within a cell (i.e., cross-bridge cycling and calcium pumping). Furthermore, only through quantitative approaches (e.g., quantitative physiology, quantitative biochemistry, and modeling) can hypotheses concerning integrated physiological function be proven. As we have seen, quantitative bookkeeping often fails (e.g., $\mathrm{Ca}^{2+}$ pumps cannot keep up with $\mathrm{Ca}^{2+}$ flux out of the SR), leading to the assessment of other mechanisms.

The use of the comparative approach has a number of important advantages that have been explored in this review. First, the advantage of using an experimental model with pure muscle fibers (fish) is incalculable and can be best understood if one envisions trying similar experiments in mammals. As reviewed in Reference 54, the main limitation of mammalian experimental models is that the muscles are typically heterogeneous (i.e., slow-twitch muscle fibers are interspersed with various types of fast-twitch muscle fibers). This fact leads to two nearly insurmountable problems preventing the type of analysis used for the swimbladder muscle. First, electromyography electrodes implanted in the mammalian muscles receive signals from fibers of all types, making it nearly impossible to discriminate which fiber type(s) are powering a particular movement. Second, any given bundle of fibers dissected from a mammalian muscle necessarily will contain more than one fiber type, making it nearly impossible to differentiate the properties of one fiber type from those of another (12). Hence, in mammals, measuring function in a pure fiber type requires going to the single-cell level, making it very difficult to perform the energetics and quantitative biochemistry experiments used in toadfish (i.e., larger preparations are needed). Furthermore, mechanics experiments in mammalian fibers require skinning, which destroys the sarcolemma membrane and precludes measurements of some important steps in the activation-relaxation cycle (e.g., $\mathrm{Ca}^{2+}$ cycling). 
A second advantage of the comparative approach is that one can study muscles at the extremes of function. On the one hand, this provides perspective on the function and mechanisms in mammalian muscle (i.e., in toadfish, we studied muscles whose speed varied by more than 50-fold, which represents close to the total speed range among vertebrates). On the other hand, studying extreme muscles can elucidate mechanisms that may otherwise be difficult to discover. For instance, by studying the fastest vertebrate muscle, we were able to show that force generation is greatly reduced in superfast muscle. The underlying mechanism appeared to be fewer attached cross-bridges. Although there had been several observations of reduced force in the muscles associated with the mammalian eye (23), these declines were small, and no mechanism had been proposed, in part because experimental studies were confounded by the heterogeneity of the muscle, but also because the mammalian eye muscles are not as fast as the swimbladder muscle and hence do not appear to have as large a reduction in force. The 10-fold reduction in force in swimbladder muscle helped us elucidate the mechanism, thereby providing evidence that the previous observations from mammalian eye muscles were not due to muscle damage or incomplete activation but may instead conform to a general design principle.

A third advantage of studying extreme function is that often it is a consequence of extreme modification to the muscle, making it technically possible to observe function that is unmeasurable in normal muscle. In the case of PARV, we devised new techniques to take advantage of the high concentration of PARV, which we predicted would provide a large postrelaxation ATP utilization signal that could be tracked. The extreme modifications for speed and synchronized function also provided the high densities of $\mathrm{Ca}^{2+}$ release sites as well as regular T-tubule disposition, which aided in the discovery of the molecular structure of the SR triad (55).

Finally, and perhaps most importantly, using lower vertebrate animal models has facilitated the establishment of paradigms that should be used when addressing issues of muscular system design and function in any animal system. By being able to bring to bear so many quantitative approaches on toadfish muscle, we have learned a good deal about superfast muscle function and muscle function in general. We believe that this type of approach is necessary, but because of the technical difficulties associated with working on mammals (and particularly humans), it will not be possible to obtain all the data required by the paradigm in the near term. Nonetheless, the paradigm still serves two important functions: (a) When certain information is not available, investigators can appreciate better the limitations required in interpreting the data they have obtained, and $(b)$ the paradigm describes the type of data that is necessary to obtain and hence provides an impetus to develop new techniques to obtain this information.

\section{ACKNOWLEDGMENTS}

This work was made possible by support from NIH grants AR38404 and AR46125 as well as the University of Pennsylvania Research Foundation. I thank Drs. Boris 
Tikunov, James Marx, and Richard Essner for their helpful comments on the manuscript.

\section{The Annual Review of Physiology is online at http://physiol.annualreviews.org}

\section{LITERATURE CITED}

1. Skoglund CR. 1961. Functional analysis of swim-bladder muscle engaged in sound production by toadfish. J. Biophys. Biochem. Cytol. 10:187-200

2. Bennett NT, Weiser M, Baker R, Bennett MVL. 1985. Toadfish sonic motor system: I. Physiology. Biol. Bull. 169:546

3. Fine ML, Mosca PJ. 1989. Anatomical study of innervation pattern of the sonic muscle of the oyster toadfish. Brain Behav. Evol. 34:265-72

4. Rome LC, Syme DA, Hollingworth S, Lindstedt SL, Baylor SM. 1996. The whistle and the rattle: the design of sound producing muscles. Proc. Natl. Acad. Sci. 93: 8095-100

5. Rome LC, Lindstedt SL. 1997. Mechanical and metabolic design of the muscular system in vertebrates. In Handbook of Physiology. Section 13, Comparative Physiology, ed. W Dantzler, pp. 1587-651. New York: Oxford Univ. Press

6. Rome LC, Funke RP, Alexander RM, Lutz GJ, Aldridge HDJN, et al. 1988. Why animals have different muscle fibre types. $\mathrm{Na}$ ture 355:824-27

7. Rome LC, Swank D, Corda D. 1993. How fish power swimming. Science 261:34043

8. Lutz GJ, Rome LC. 1994. Built for jumping: the design of frog muscular system. Science 263:370-72

9. Marsh RL, Olson JM, Guzik SK. 1992. Mechanical performance of scallop adductor muscle during swimming. Nature 357:411-13

10. Rome LC, Kushmerick MJ. 1983. The energetic cost of generating isometric force as a function of temperature in isolated frog muscle. Am. J. Physiol. Cell Physiol. 244:C100-9

11. Rome LC. 1982. The energetic cost of running with different muscle temperatures in Savannah monitor lizards. J. Exp. Biol. 97:411-26

12. Rome LC. 1998. Some advances in integrative muscle physiology. Comp. Biochem. Physiol. B 120:51-72

13. Josephson RK. 1985. Mechanical power output from striated muscle during cyclic contraction. J. Exp. Biol. 114:493-512

14. Young IS, Rome LC. 2001. Mutually exclusive muscle designs: power output of locomotory and sonic muscles of the oyster toadfish (Opsanus tau). Proc. R. Soc. London Ser. B 268:1975-80

15. Johnson TP, Johnston IA. 1991. Power output of fish muscle fibres performing oscillatory work: effects of acute and seasonal temperature change. J. Exp. Biol. 157:40923

16. Josephson RK. 1985. The mechanical power output of a tettigoniid wing muscle during singing and flight. J. Exp. Biol. 117:357-68

17. Baylor SM, Hollingworth S. 1988. Fura-2 calcium transients in frog skeletal muscle fibres. J. Physiol. 403:151-92

18. Appelt D, Shen V, Franzini-Armstrong C. 1991. Quantitation of Ca ATPase, feet and mitochondria in super fast muscle fibers from the toadfish, Opsanus tau. J. Muscle Res. Cell Motil. 12:543-52

19. Baylor SM, Hollingworth S. 1998. Model of sarcomeric $\mathrm{Ca}^{2+}$ movements, including ATP $\mathrm{Ca}^{2+}$ binding and diffusion, during activation of frog skeletal muscle. J. Gen. Physiol. 112:297-316 
20. Jiang Y, Johnson JD, Rall JA. 1996. Parvalbumin relaxes frog skeletal muscle when the sarcoplasmic reticulum Ca-ATPase is inhibited. Am. J. Physiol. Cell Physiol. 270:C411-17

21. Hou TT, Johnson JD, Rall JA. 1991. Parvalbumin content and $\mathrm{Ca}^{2+}$ and $\mathrm{Mg}^{2+}$ dissociation rates correlated with changes in relaxation rate of frog muscle fibres. J. Physiol. 441:285-304

22. Wahr PA, Johnson JD, Rall JA. 1998. Determinants of relaxation rate in skinned frog skeletal muscle fibers. Am. J. Physiol. 274:C1608-15

23. Rome LC, Cook C, Syme DA, Connaughton MA, Ashley-Ross M, et al. 1999. Trading force for speed: Why superfast crossbridge kinetics leads to superlow forces. Proc. Natl. Acad. Sci. USA 96: 5826-31

24. Brenner B. 1988. Effect of $\mathrm{Ca}^{2+}$ on crossbridge turnover kinetics in skinned single rabbit psoas fibers: implications for regulation of muscle contraction. Proc. Natl. Acad. Sci. USA 85:3265-69

25. Rome LC, Lindstedt SL. 1998. The quest for speed: muscles built for high frequency contractions. News Physiol. Sci. 13:261-68

26. Barany M. 1967. ATPase activity of myosin correlated with speed of muscle shortening. J. Gen. Physiol. 50:197-218

27. Stienen GJM, Zaremba R, Elzinga G. 1995. ATP utilization of calcium uptake and force production in skinned muscle fibres of Xenopus laevis. J. Physiol. 482:109-22

28. Rome LC, Klimov AA. 2000. Superfast contractions without superfast energetics: ATP usage by SR-Ca ${ }^{2+}$ pumps and crossbridges in the toadfish swimbladder muscle. J. Physiol. 526:279-98

29. Tikunov BA, Sweeney HL, Rome LC. 2001. Quantitative electrophoretic analysis of myosin heavy chains in single muscle fibers. J. Appl. Physiol. 90:1927-35

30. Fine ML. 1978. Seasonal and geographical variation of the mating call of the oyster toadfish Opsanus tau L. Oecologia 36:4557
31. Edds-Walton P, Mangiamele L, Rome LC. 2002. Boatwhistles from oyster toadfish (Opsanus tau) around Waquoit Bay, Massachusetts. J. Bioacoust. 13:153-73

32. Martonosi AN, Beeler TJ. 1983. Mechanism of $\mathrm{Ca}^{2+}$ transport by sarcoplasmic reticulum. In Handbook of Physiology, ed. LD Peachy, pp. 417-85. Bethesda, MD: Am. Physiol. Soc.

33. Young IS, Harwood CL, Rome LC. 2003. Cross-bridge blocker BTS permits the direct measurement of $\mathrm{Ca}^{2+}$ pump ATP utilization in skinned toadfish swimbladder muscle fibers. Am. J. Physiol. Cell Physiol. 285:C781-87

34. Somlyo AV, McClellan G, GonzalezSerratos H, Somlyo AP. 1985. Electron probe X-ray microanalysis of post-tetanic $\mathrm{Ca}^{2+}$ and $\mathrm{Mg}^{2+}$ movements across the sarcoplasmic reticulum in situ. J. Biol. Chem. 260:6801-7

35. Baylor SM, Chandler WK, Marshall MW. 1983. Sarcoplasmic reticulum calcium release in frog skeletal muscle fibres extimated from Arsenazo III calcium transients. J. Physiol. 344:625-66

36. Cheung A, Dantzig JA, Hollingworth S, Baylor SM, Goldman YE, et al. 2002. A small-molecule inhibitor of skeletal muscle myosin II. Nat. Cell Biol. 4:8388

37. Harwood CL, Young IS, Rome LC. 2001. Biophys. J. 80:A271 (Abstr.)

38. Jong DS, Pape PC, Geibel J, Chandler WK. 1996. Sarcoplasmic reticulum calcium release in frog cut muscle fibers in the presence of a large concentration of EGTA. Soc. Gen. Physiol. Ser. 51:255-68

39. Pape PC, Jong DS, Chandler WK. 1995. Calcium release and its voltage dependence in frog cut muscle fibers equilbrated with 20 mM EGTA. J. Gen. Physiol. 106:259336

40. Hollingworth S, Baylor SM. 1996. Sarcoplasmic reticulum (SR) calcium release in intact superfast toadfish swimbladder (TSB) and fast frog twitch fibers. Biophys. J. 70:A235 (Abstr.) 
41. Heizman CW, Berchtold MW, Rowlerson AM. 1982. Correlations of parvalbumin concentration with relaxation speed in mammalian muscles. Proc. Natl. Acad. Sci. USA 79:7243-47

42. Klug GA, Leberer E, Leisner E, Simoneau J, Pette D. 1988. Relationship between parvalbumin content and the speed of relaxation in chronically stimulated rabbit fasttwitch muscle. Pflugers Arch. 411:126-31

43. Muntener M, Kaser L, Weber J, Berchtold MW. 1995. Increase of skeletal muscle relaxation speed by direct injection of parvalbumin cDNA. Proc. Natl. Acad. Sci. USA 92:6504-8

44. Szatkowski ML, Westfall MV, Gomez CA, Wahr PA, Michele DE, et al. 2001. In vivo acceleration of heart relaxation performance by parvalbumin gene delivery. $J$. Clin. Invest. 107:191-98

45. Hou TT, Johnson JD, Rall JA. 1992. Effect of temperature on relaxation rate and $\mathrm{Ca}^{2+}$, $\mathrm{Mg}^{2+}$ dissociation rates from parvalbumin of frog fibres. J. Physiol. 449:399-410

46. Homsher E, Lacktis J, Yamada T, Zohman G. 1987. Repriming and reversal of the isometric unexplained enthalpy in frog skeletal muscle. J. Physiol. 393:157-70

47. Rall JA. 1989. Relationship of isometric unexplained energy production to parvalbumin content in frog skeletal muscle. In Muscle Energetics, ed. R.J. Paul, G. Elzinga, K. Yamada, pp. 117-26. New York: A.R. Liss, Inc.
48. Tikunov BA, Klimov AA, Rome LC. 2003. Biophys. J. 84(2):A1892 (Abstr.)

49. Bass AH, Marchaterre MA. 1989. Soundgenerating (sonic) motor system in teleost fish (Porichthys notatus): sexual polymorphism in the ultrastructure of myofibrils. $J$. Comp. Neurol. 286:141-53

50. Bass AH, Grober MS. 2001. Social and neural modulation of sexual plasticity in teleost fish. Brain Behav. Evol. 57:293-300

51. Lewis MK, Nahirney PC, Chen V, Adhikari $\mathrm{BB}$, Wright J, et al. 2003. Concentric intermediate filament lattice links to specialized Z-band junctional complexes in sonic muscle fibers of the type I male midshipman fish. J. Struct. Biol. 143:56-71

52. Schaeffer PJ, Conley KE, Lindstedt SL. 1996. Structural correlates of speed and endurance in skeletal muscle: the rattlesnake tailshaker muscle. J. Exp. Biol. 199:351-58

53. Elemans CP, Spierts IL, Muller UK, van Leeuwen JL, Goller F. 2004. Bird song: Superfast muscles control dove's trill. Nature 431:146

54. Rome LC. 2002. The design of vertebrate muscular systems: comparative and integrative approaches. Clin. Orthop. 403S:S59-76

55. Block BA, Imagawa T, Campbell KP, Franzini-Armstrong C. 1988. Structural evidence for direct interaction between the molecular components of the transverse tubule/sarcoplasmic reticulum junction in skeletal muscle. J. Cell Biol. 107:2587-600 